\title{
Different Dosages of Corticosteroid and Routes of Administration in Mandibular Third Molar Surgery: a Systematic Review
}

\author{
Marie Kjærgaard Larsen ${ }^{1}$, Thomas Kofod ${ }^{2}$, Ann-Eva Christiansen ${ }^{3}$, Thomas Starch-Jensen ${ }^{1}$ \\ ${ }^{1}$ Department of Oral and Maxillofacial Surgery, Aalborg University Hospital, Aalborg, Denmark. \\ ${ }^{2}$ Department of Oral and Maxillofacial Surgery, Rigshospitalet, Copenhagen University Hospital, Copenhagen, Denmark. \\ ${ }^{3}$ Unit of Epidemiology and Biostatistics, Aalborg University Hospital, Aalborg, Denmark.
}

\author{
Corresponding Author: \\ Marie Kjærgaard Larsen \\ Department of Oral and Maxillofacial Surgery \\ Aalborg University Hospital \\ 18-22 Hobrovej, DK-9000 Aalborg \\ Denmark \\ Phone: +45 97662795 \\ Fax: +45 97662825 \\ E-mail: marie.kjaergaard@rn.dk
}

\section{ABSTRACT}

Objectives: The objective of the present systematic review was to test the hypothesis of no difference in facial swelling, pain and trismus after surgical removal of mandibular third molar with different dosages of corticosteroids and administration routes.

Material and Methods: A MEDLINE (PubMed), Embase database and Cochrane Library search in combination with a handsearch of relevant journals was conducted by including randomized controlled trials published in English until $1^{\text {st }}$ December 2017.

Results: Seven studies fulfilled the inclusion criteria. Considerable variation in the included studies prevented meta-analysis from being performed. Preoperative submucosal injection of corticosteroids significantly diminishes facial swelling, pain and trismus compared with placebo. However, different dosages of corticosteroid and administration routes reveal contrary results indicating that administration of a higher dosage of corticosteroids do not necessarily cause a further decrease in facial swelling, pain and trismus.

Conclusions: Consequently, the optimal dosage of corticosteroids and administration route for diminishing postsurgical morbidity and improve quality of life after surgical removal of mandibular third molar is presently unknown. Therefore, further well-designed randomized clinical trials including a standardised protocol, patient-reported outcome measures and three-dimensional analysis of facial swelling is needed.

Keywords: corticosteroids; dentistry; edema; molar; pain; trismus.

\section{Accepted for publication: 25 June 2018}

\section{To cite this article:}

Larsen MK, Kofod T, Christiansen AE, Starch-Jensen T.

Different Dosages of Corticosteroid and Routes of Administration in Mandibular Third Molar Surgery: a Systematic Review J Oral Maxillofac Res 2018;9(2):e1

URL: http://www.ejomr.org/JOMR/archives/2018/2/e1/v9n2e1.pdf

doi: $10.5037 /$ jomr.2018.9201 


\section{INTRODUCTION}

Removal of impacted mandibular third molar (M3) is one of the most common performed surgical interventions in dental practice and is often associated with facial swelling, pain and trismus [1]. These postoperative sequelae arise as a result of the natural inflammatory response and often influence the patients' ability to perform their daily activities and compromise the immediate quality of life [2-5]. Age, gender, medical status, smoking, poor oral hygiene, anatomy, time length of surgical procedure and experience of the surgeon has been associated with an increased risk of postoperative sequelae after surgical removal of M3 [6-8]. Various treatment modalities have been attempted to prevent or diminish the initial inflammatory response associated with surgical removal of M3 including pharmacological therapies, cryotherapy, local compression and surgical drains [9-15].

Corticosteroids are a class of steroid hormones that are produced in the adrenal cortex of vertebrates [16]. The synthetic analogues of these hormones are the most commonly preferred pharmaceutical agents for decreasing the severity of the natural inflammatory response after surgical removal of M3. Corticosteroids suppress each stage of the initial inflammatory response comprising a decrease in the permeability and capillary dilatation by inhibiting the production of vasoactive substances and reducing the amount of cytokines $[\underline{17}, \underline{18}]$. Moreover, prostaglandin formation is also inhibited by corticosteroids, thereby facilitating some analgesic effects $[19,20]$. The potential side effects of corticosteroids depend on the intensity and duration of the treatment. Side effects to a single dose of corticosteroids have never been described in oral surgery [21-23]. Moreover, postoperative infection due to the immunosuppressive effect of corticosteroid has not been observed in oral surgery [24].

Corticosteroids can be administrated systemically or by local injection in the surgical area. Corticosteroids are classified according to their potency, duration of action, relative mineral corticosteroid and plasma half-life (Table 1). Dexamethasone, methylprednisolone and betamethasone are the most commonly administered types of corticosteroids for diminishing the initial inflammatory response after surgical removal of impacted M3. As documented in systematic reviews, various dosages of corticosteroids and durations of treatment as well as different routes of administration have been used revealing dissimilar effects on facial swelling, pain and trismus $[\underline{21-23}, \underline{25}, \underline{26}]$. Numerous systematic reviews have concluded that short-term administration of corticosteroids significantly reduces the degree of facial swelling, pain and trismus after surgical removal of impacted M3 $[\underline{22}, \underline{23}, \underline{25}, \underline{26}]$. Moreover, parenteral and preoperative prescription of corticosteroids seems to be superior compared to other routes and time of administration [25]. However, many of the included studies disclosed huge heterogeneity, high risk of bias and various confounding variables. Moreover, randomized controlled trials (RCT) comparing different dosages of corticosteroids with similar routes of administration or similar dosage of corticosteroids with different routes of administration are scarce $[23,25]$. A recent published systematic review and meta-analysis concluded that submucosal injection of dexamethasone significantly diminished facial swelling and pain after surgical removal of impacted M3, whereas no statistically significant difference in trismus was revealed between dexamethasone and placebo [26]. Moreover, an improved outcome for a specific dosage of dexamethasone was not identified in the meta-analysis [26]. These results are in accordance with a newly published systematic review and meta-analysis assessing systematic corticosteroids in orthognathic surgery disclosing that systemic corticosteroids is not supported by strong scientific evidence [27].

Consequently, there seems to be no clear practice consensus regarding the most effective regime for administration of corticosteroids to diminish facial swelling, pain and trismus after surgical removal of

Table 1. Duration of action and anti-inflammatory potency of corticosteroids

\begin{tabular}{|c|c|c|c|}
\hline Corticosteroid & $\begin{array}{c}\text { Duration of } \\
\text { action }\end{array}$ & $\begin{array}{c}\text { Anti-inflammatory } \\
\text { potency }\end{array}$ & $\begin{array}{l}\text { Equivalent } \\
\text { dose }\end{array}$ \\
\hline Cortisol & Short $(<12$ hours $)$ & 1 & $20 \mathrm{mg}$ \\
\hline Prednisone & \multirow{3}{*}{$\begin{array}{l}\text { Intermediate } \\
\text { (12 - } 36 \text { hours) }\end{array}$} & 4 & $5 \mathrm{mg}$ \\
\hline Prednisolone & & 4 & $5 \mathrm{mg}$ \\
\hline Methylprednisolone & & 5 & $4 \mathrm{mg}$ \\
\hline Dexamethasone & \multirow{2}{*}{ Long ( $>36$ hours) } & 25 & $0.75 \mathrm{mg}$ \\
\hline Bethamethasone & & 25 & $0.75 \mathrm{mg}$ \\
\hline
\end{tabular}


impacted M3. Therefore, the objective of the present systematic review was to test the hypothesis of no difference in facial swelling, pain or trismus after surgical removal of impacted M3 with different dosages of corticosteroids and routes of administration.

\section{MATERIAL AND METHODS Protocol and registration}

The present systematic review was conducted in accordance with the Preferred Reporting Items for Systematic reviews and Meta-Analyses (PRISMA) statement for reporting systematic reviews [28]. The methods of the analysis, inclusion and exclusion criteria were specified in advance and documented in a protocol. The protocol was registered in PROSPERO, an international prospective register of systematic reviews. It can be accessed at: https://www.crd.york.ac.uk/PROSPERO/, with the registration number: CRD42017071955.

\section{Types of publications}

The review included studies on humans. Letters, editorials, $\mathrm{PhD}$ theses, letters to the editor, case reports, abstracts, technical reports, conference proceedings, animal or in vitro studies and literature review papers were excluded.

\section{Types of studies}

The review included all RCT comparing facial swelling, pain and trismus after surgical removal of mandibular M3 with different dosages of corticosteroids or routes of administration.

\section{Types of outcome measures}

The outcome measures are outlined in Table 2.

\section{Information sources}

The search strategy incorporated examinations of electronic databases, supplemented by a thorough hand-search page by page of relevant journals (Figure 1). The manual search also included the bibliographies of all articles selected for full-text screening as well as previously published reviews relevant for the present systematic review. Two of the reviewers (MKL, TSJ) performed the search. If disagreements occurred, another reviewer was consulted (TK).

\section{Search strategy}

A Medline (Pubmed), Embase and Cochrane Library search was conducted. Human studies published in English until 1 $1^{\text {st }}$ December 2017 were included. The search strategy was performed in collaboration with a medical librarian utilized a combination of Medical subject heading (MeSH) and free text terms. The search strategy is outlined in Appendix 1 - 3 .

\section{Selection of studies}

The PRISMA flow diagram presents an overview of the selection process (Figure 1). The titles of the identified reports were initially screened. The abstract was assessed when the title indicated that the study fulfilled the inclusion criteria. Full-text analysis was carried out when the abstract was unavailable or when the abstract indicated that the inclusion criteria were fulfilled. The references of the identified papers were cross-checked for unidentified articles. The study selection was performed by two reviewers (MKL, TSJ). If disagreements occurred, another reviewer was consulted (TK).

\section{Study eligibility}

The inclusion criteria were developed using the PICOS guidelines (Table 3 ).

\section{Inclusion criteria}

Human RCT assessing the treatment outcome following surgical removal of M3 with the use of different dosages or administration routes of corticosteroids were included by addressing the previously described outcome measures. Moreover, at least 20 patients should be included and the surgeon

Table 2. Outcome measures

\begin{tabular}{l}
\hline Swelling, evaluated by angles or distances between different reference points of the face \\
\hline Pain, evaluated by visual analog scale or consumption of painkillers \\
\hline Trismus, evaluated by interincisal distance \\
\hline Patient-reported outcome measures and assessment of quality of life, evaluated by questionnaires and visual analog scale \\
\hline Complications
\end{tabular}




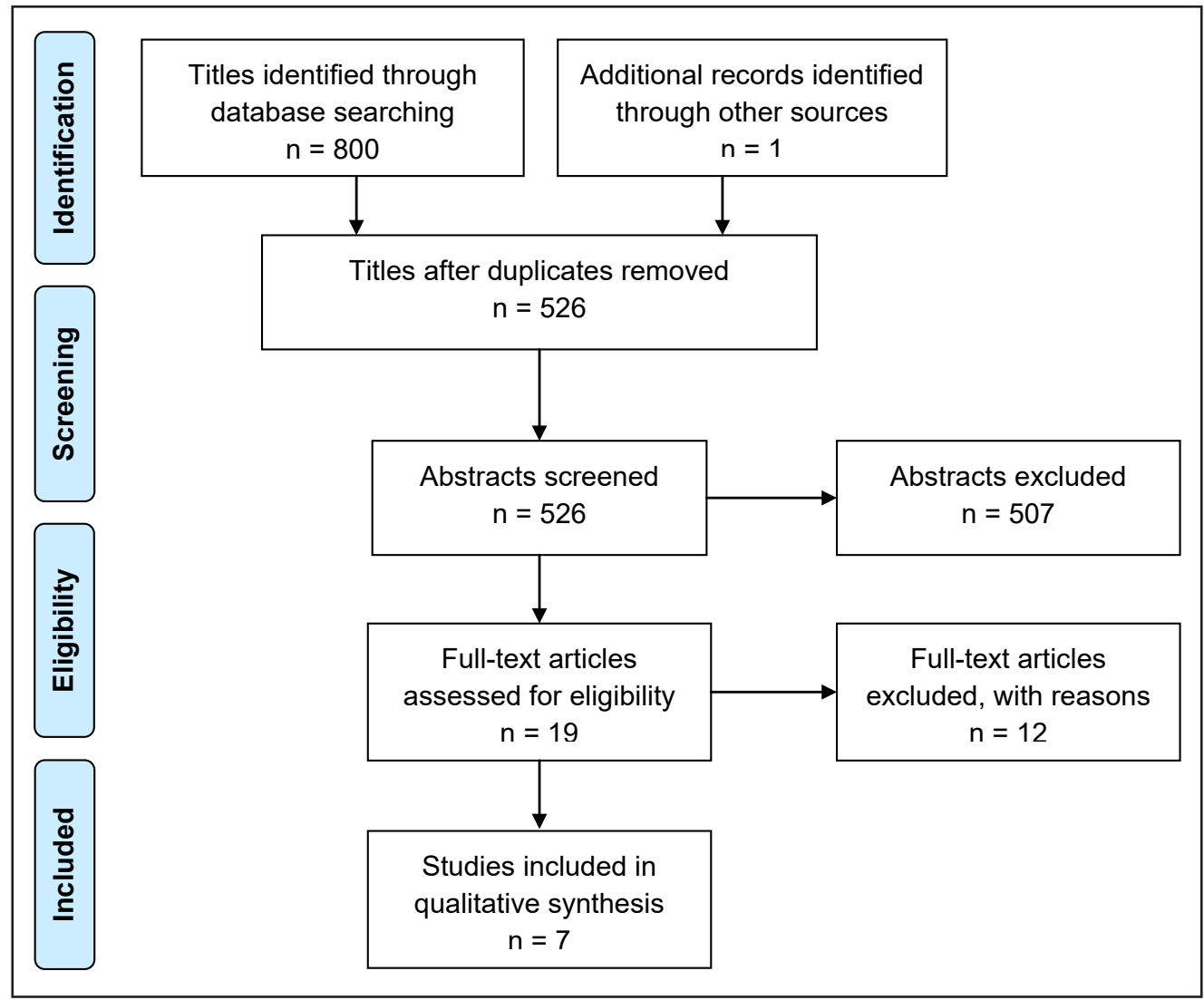

Figure 1. PRISMA flow diagram demonstrating the results of the systematic literature search.

Table 3. PICOS guidelines

\begin{tabular}{l|l}
\hline Patient and population (P) & All adult healthy patients (> 15 years) with indications for surgical removal of mandibular third molars. \\
\hline Intervention (I) & Surgical removal of mandibular third molars in conjunction with administration of corticosteroids. \\
\hline $\begin{array}{l}\text { Comparator or control } \\
\text { group (C) }\end{array}$ & $\begin{array}{l}\text { Surgical removal of mandibular third molars with different dosage or administration routes of } \\
\text { corticosteroids. }\end{array}$ \\
\hline Outcomes (O) & Facial swelling, pain, trismus, complications, patient-reported outcome measures, quality of life measures. \\
\hline Study design (S) & $\begin{array}{l}\text { Randomized controlled trials in humans with the aim of comparing the postoperative outcome following } \\
\text { surgical removal of mandibular third molars with different doses or administration routes of corticosteroids. }\end{array}$ \\
\hline Focused question & $\begin{array}{l}\text { Are there any differences in the postoperative outcome following surgical removal of mandibular third } \\
\text { molars with different doses or administration routes of corticosteroids? }\end{array}$ \\
\hline
\end{tabular}

as well as assessors should be blinded. Inclusion and exclusion criteria and the used surgical technique should be clearly specified. In addition, the anatomical location and the surgical difficulty of the impacted M3 should be specified according to a well-known classification system. Moreover, the methods used for assessment of facial swelling, pain and trismus should be useful for statistical analysis.

\section{Exclusion criteria}

The following exclusion criteria were applied: letters to the editor, case reports, cohort-studies, case-series, retrospective studies, technical reports, conference proceedings, animal or in vitro studies and review papers. Moreover, studies with insufficient description of patient selection, surgical procedure, dosage of corticosteroids and administration route as well as studies including medically compromised patients were excluded. Moreover, non-blinded RCT and studies comparing the effects of corticosteroids with other pharmacological therapies or combining corticosteroids with other medications were also excluded.

\section{Data extraction}

Data were extracted by two of the reviewers (MKL, TSJ) according to a data-collection form ensuring systematic recording of the outcome measures. In addition, relevant characteristics of the study were recorded. The corresponding author was contacted 
by e-mail in the absence of important information or ambiguities.

\section{Data items}

The following items were collected from the included studies and arranged in the following fields: authors and year of publication, total number of patients, mean age in year, sex distribution, groups, number of patients in the groups, administration time, route of administration, type of corticosteroid, dosage of corticosteroid, dosage of corticosteroid converted to dosage in dexamethasone, swelling, pain and trismus.

\section{Assessment of methodological quality}

The quality assessment of the included studies was undertaken by one reviewer (MKL) as part of the data extraction process. The Cochrane Collaboration's tool for assessing risk of bias was used as a methodological quality rating system and the classification of the risk of bias potential for each study was based on seven criteria as outlined in Table 4 [29].

\section{Statistical analysis}

Meta-analyses were to be conducted only if there were studies of similar comparison, reporting identical outcome measures. However, the included studies revealed considerable variations in study design, i.e. administration routes, dosages, observation period and postoperative measurements. Therefore, metaanalysis was not applicable. However, the amount of facial swelling and trismus among the included studies were estimated with $95 \%$ confidence interval (CI) based on an estimated standard error:

$$
\mathrm{SE}=\frac{\mathrm{SD}_{\text {difference }}}{\sqrt{\text { number of patients }}}
$$

where the estimated standard deviation (SD) was calculated by:

$$
\mathrm{SD}_{\text {difference }}=\sqrt{\mathrm{SD}_{\text {preoperative }}^{2}+\mathrm{SD}_{\text {postoperative }}^{2}}
$$

The CI were calculated by:

$$
\text { lower limit }=\text { mean }-1.96 \times \mathrm{SE}
$$

and

$$
\text { upper limit }=\text { mean }+1.96 \times \text { SE }
$$

\section{RESULTS \\ Study selection}

Article review and data extraction were performed according to the PRISMA flow diagram (Figure 1). A total of 800 titles were identified and 525 abstracts were reviewed. Full-text analysis included 18 articles and seven RCT were finally included [30-35]. One article was included as the result of hand-searching [흐].

\section{Exclusion of studies}

Twelve studies were excluded after full-text assessment. The reasons for excluding the studies were as follow: no blinding or inadequate description of blinding procedure $[15, \underline{37-45}]$, less than 20

\begin{tabular}{|c|c|c|c|c|c|c|c|c|c|c|c|c|c|c|}
\hline \multirow[b]{2}{*}{ Study } & \multirow{2}{*}{$\begin{array}{c}\text { Year of } \\
\text { publication }\end{array}$} & \multicolumn{3}{|c|}{ Patients } & \multicolumn{7}{|c|}{ Materials and methods } & \multicolumn{3}{|c|}{ Outcome measures } \\
\hline & & Number & $\begin{array}{c}\text { Age } \\
\text { (years) }\end{array}$ & Sex & & $\mathbf{N}$ & AT & $\mathbf{A R}$ & $\mathrm{CO}$ & DO & $\begin{array}{l}\text { DO in } \\
\text { DEX }\end{array}$ & Swelling & Pain & Trismus \\
\hline \multirow{3}{*}{$\begin{array}{l}\text { Lim and Ngeow } \\
{[30]}\end{array}$} & \multirow{3}{*}{2017} & \multirow{3}{*}{60} & \multirow{3}{*}{25 (SD 4) } & \multirow{3}{*}{$\begin{array}{c}11 \mathrm{M} ; \\
49 \mathrm{~F}\end{array}$} & $\mathrm{~A}$ & 20 & \multirow{3}{*}{ PREOP } & \multirow{3}{*}{ S.m. } & DEX & $4 \mathrm{mg}$ & $4 \mathrm{mg}$ & \multirow{3}{*}{ A, B $<$ C } & \multirow{3}{*}{$\begin{array}{c}* \\
\mathrm{~B}<\mathrm{A}, \mathrm{C}\end{array}$} & \multirow{3}{*}{$\begin{array}{c}* \\
\mathrm{~A}, \mathrm{~B}<\mathrm{C}\end{array}$} \\
\hline & & & & & B & 20 & & & MET & $40 \mathrm{mg}$ & $7.5 \mathrm{mg}$ & & & \\
\hline & & & & & $\mathrm{C}$ & 20 & & & - & $0 \mathrm{mg}$ & $0 \mathrm{mg}$ & & & \\
\hline \multirow{2}{*}{ Üstün et al. [32] } & \multirow{2}{*}{2003} & \multirow{2}{*}{20} & \multirow{2}{*}{$21.9(\mathrm{SD} 2.6)$} & \multirow{2}{*}{ NM } & $\mathrm{A}$ & 20 & \multirow{2}{*}{ PREOP } & \multirow{2}{*}{ i.v. } & \multirow{2}{*}{ MET } & $1.5 \mathrm{mg} / \mathrm{kg}$ & $0.5 \mathrm{mg} / \mathrm{kg}$ & \multirow{2}{*}{-} & \multirow{2}{*}{ - } & \multirow{2}{*}{ - } \\
\hline & & & & & $\mathrm{B}$ & 20 & & & & $3 \mathrm{mg} / \mathrm{kg}$ & $1 \mathrm{mg} / \mathrm{kg}$ & & & \\
\hline \multirow{2}{*}{$\begin{array}{l}\text { Laureano Filho } \\
\text { et al. [33] }\end{array}$} & \multirow{2}{*}{2008} & \multirow{2}{*}{60} & \multirow{2}{*}{19.5} & $30 \mathrm{M}$ & $\mathrm{A}$ & 30 & \multirow{2}{*}{ PREOP } & \multirow{2}{*}{ Oral } & \multirow{2}{*}{ DEX } & $8 \mathrm{mg}$ & $8 \mathrm{mg}$ & \multirow{2}{*}{$*$} & \multirow[b]{2}{*}{ 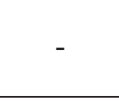 } & \multirow{2}{*}{$*$} \\
\hline & & & & $30 \mathrm{~F}$ & $\mathrm{~B}$ & 30 & & & & $4 \mathrm{mg}$ & $4 \mathrm{mg}$ & & & \\
\hline Agostinho et al. & 2014 & 27 & $217(\mathrm{SD} 6.4)$ & $10 \mathrm{M}$ & $\mathrm{A}$ & 27 & PREOP & Oral & DEX & $4 \mathrm{mg}$ & $4 \mathrm{mg}$ & & & \\
\hline$[34]$ & 2014 & 21 & $21.7(\mathrm{SD} 6.4)$ & $17 \mathrm{~F}$ & $\mathrm{~B}$ & 27 & PREOP & Oral & $D E X$ & $12 \mathrm{mg}$ & $12 \mathrm{mg}$ & - & - & - \\
\hline
\end{tabular}
participants [46] and insufficient description of the surgical procedure [47].

Table 4. Included studies assessing different doses of corticosteroids

*Significant difference between groups, $\mathrm{P}<0.05$.

$\mathrm{AR}=$ administration route; $\mathrm{AT}=$ administration time; $\mathrm{CO}=$ corticosteroid; $\mathrm{DEX}=$ dexamethasone; $\mathrm{DO}=$ dose; i.v $=$ intravenous; $\mathrm{MET}=$ methylprednisolone; $\mathrm{N}=$ number of interventions; $\mathrm{PREOP}=$ preoperatively; $\mathrm{S} . \mathrm{m} .=$ submucosal; $\mathrm{M}=$ male; $\mathrm{F}=$ female. 


\section{Study characteristics}

The included studies in the present systematic review consisted of seven hospital-based blinded RCT [30-36]. Different dosages of corticosteroids were assessed in four studies [30,32-34]. Different administration routes of corticosteroids were assessed in one study [36], and two studies assessed different dosages and administration routes of corticosteroids [31,35]. Facial swelling, pain and trismus were assessed in all of the included studies, whereas patient-reported outcome measures and quality of life assessment were not reported in any of the included studies. The sample size varied between 20 and 200 patients. A description of the used power calculation of sample size was not reported in any of the included studies. The method used for randomization was described in two studies, involving a random numbers table [30] or opaque envelopes [31]. Age distribution was described in five studies [31-34,36]. Gender distribution was solely described in three studies $[30,34,36]$. The surgical experience of the surgeon was reported in two of the included studies $[32,33]$. The duration of the operations were recorded in five studies [31-34,36]. Smoking habits among the included patients were not reported in any of the included studies. Different conditions and types of analgesics were used in the included studies. Regular dosages of paracetamol in the postoperative period were prescribed in three studies $[\underline{31}, \underline{33}, \underline{36}]$. Dosages of $500 \mathrm{mg}$ paracetamol were prescribed in two studies [1, $\underline{36}]$, and dosages of $750 \mathrm{mg}$ paracetamol were prescribed in one study [33]. Pain was measured in the consumption of analgesics in three studies $[30,32, \underline{34}]$. Paracetamol in respective dosages of $500 \mathrm{mg}$ [32] and $750 \mathrm{mg}$ [34] were used in two studies, and $250 \mathrm{mg}$ mefanamic acid was used in one study [30]. The use of postoperative analgesic was not described in one study [35]. Different types and dosages of antibiotics were used in five of the included studies $[\underline{30-32,35}, \underline{36}]$. Amoxicillin [36] and phenoxymethylpenicillin [32] were prescribed preoperatively in two studies, whereas amoxicillin $[\underline{30}, \underline{31}]$ and amoxicillin with clavulanic acid [ $\underline{35}]$ were prescribed postoperatively in three studies. The use of antibiotics were not prescribed in two studies $[33,34]$.

\section{Different dosages of corticosteroids}

The use of different dosages of corticosteroids after surgical removal of impacted M3 has been assessed in four studies [30,32-34] (Table 4).

Twenty-six patients with symmetrically impacted M3 were random assigned to one hour preoperative intravenous administration of $1.5 \mathrm{mg} / \mathrm{kg}$ or $3 \mathrm{mg} /$ $\mathrm{kg}$ methylprednisolone in a split-mouth and doubleblinded RCT [32]. The impacted M3 were classified according to the Pell and Gregory system with equivalent degree of surgical difficulty [32]. The surgical procedure was separated by three weeks and performed by the same surgeon with patients under local anaesthesia. Facial swelling was evaluated using a tape measuring method described by Gabka and Matsumura [48]. Pain was determined on a daily basis using a questionnaire and a visual analogue scale (VAS). Moreover, the number of analgesics consumed was also registered. Trismus was determined by measuring maximum interincisal opening. Assessment of facial swelling and trismus were obtained before surgical intervention and two and seven days after surgery. A total of six patients were excluded because the questionnaire was not completed properly and the time differences between the surgeries differed more than five minutes [32].

Thirty patients with symmetrically impacted M3 were random assigned to one hour preoperative oral consumption of $4 \mathrm{mg}$ or $8 \mathrm{mg}$ oral dexamethasone in a split-mouth and double-blinded RCT [33]. The impacted M3 were classified according to Winter's classification with similar degree of surgical difficulty [49]. The surgical procedure was separated by fifteen days and performed by the same surgeon with patients under local anaesthesia. Facial swelling was evaluated through facial reference points' variation. Pain was evaluated using a VAS. Trismus was determined by measuring maximum interincisal opening. Assessment of facial swelling and trismus were obtained before surgical intervention and one and two days after surgery. All patients participated in the follow-up examination [33].

Thirty-four patients with symmetrically impacted M3 were random assigned to one hour preoperative oral consumption of $4 \mathrm{mg}$ or $12 \mathrm{mg}$ dexamethasone in a split-mouth and double-blinded RCT [34]. The impacted M3 were classified according to the Pell and Gregory system with similar degree of surgical difficulty [50]. The surgical procedure was separated by fifteen days and performed by the same surgeon with patients under local anaesthesia. Facial swelling was evaluated through facial reference points' variation. Pain was evaluated using a VAS. Moreover, the number of analgesics consumed was also registered. Trismus was determined by measuring maximum interincisal opening. Assessment of facial swelling and trismus were obtained before surgical intervention and one and two days after surgery. A total of seven patients were excluded due to pregnancy and because they did not show up at their 
postoperative appointments or did not return after the first surgery [34].

Sixty-five patients with symmetrically impacted M3 were random assigned to preoperative submucosal injection of $4 \mathrm{mg}$ dexamethasone, 40 $\mathrm{mg}$ methylprednisolone or placebo in a doubleblinded RCT [30]. The impacted M3 were classified according to the Pell and Gregory system with similar degree of surgical difficulty [미]. The same surgeon performed the surgical procedure with patients under local anaesthesia. Facial swelling was evaluated through facial reference points' variation. Pain was evaluated using a VAS. Moreover, the number of analgesics consumed was also registered. Trismus was determined by measuring maximum interincisal opening. Assessment of facial swelling and trismus were obtained before surgical intervention and one, two, five and seven days after surgery. No information of drop-outs or withdrawals was provided [30].

\section{Different administration routes of corticosteroids}

Different administration routes of corticosteroids after surgical removal of impacted M3 have been assessed in one study [36].

Twenty patients with symmetrically impacted M3 were random assigned to one hour preoperative oral consumption of $8 \mathrm{mg}$ oral dexamethasone or intramuscular injection (deltoid muscle) of 8 mg dexamethasone in a split-mouth and doubleblinded RCT [36]. The impacted M3 were classified according to their horizontal angulation with similar degree of surgical difficulty but no classification system was specified. The surgical procedure was separated by one month and performed by the same surgeon with patients under local anaesthesia. Facial swelling was evaluated by different facial reference points/landmarks. Pain was evaluated using VAS. Moreover, the number of analgesics consumed was also registered. Trismus was determined by measuring maximum interincisal opening. Assessment of facial swelling and trismus were obtained before surgical intervention and one, three and seven days after surgery. No information of drop-outs or withdrawals was provided [ $\underline{36}]$.

\section{Different dosages and administration routes corticosteroids}

Different dosages and administration routes of corticosteroids after surgical removal of impacted M3 have been assessed in two studies [31, 35] .

Forty-three patients were allocated to endo-alveolar administration of $4 \mathrm{mg}$ or $10 \mathrm{mg}$ dexamethasone or submucosal injection $10 \mathrm{mg}$ dexamethasone in a splitmouth and double-blinded RCT [35]. The impacted M3 were classified according to the Pell and Gregory system with similar degree of surgical difficulty [50]. The surgical procedure was separated by at least four weeks and performed by the same surgeon with patients under local anaesthesia. Facial swelling was evaluated by different facial reference points'/ landmarks. Pain was evaluated using VAS. Trismus was determined by measuring maximum interincisal opening. Assessment of facial swelling and trismus were obtained before surgical intervention and two and seven days after surgery. No information of dropouts or withdrawals was provided [35].

Two hundred patients with symmetrically impacted M3 were random assigned to one hour preoperative oral consumption of $8 \mathrm{mg}$ dexamethasone or intravenous administration of $4 \mathrm{mg}$ dexamethasone in a split-mouth and double-blinded RCT [31]. The impacted M3 were classified according to the Pell and Gregory system with similar degree of surgical difficulty according to Pederson's Index [50]. The surgical procedure was separated by two weeks and performed with patients under local anaesthesia. No information was provided about the number of surgeons. Facial swelling was evaluated using facial reference points' variation according to Neupert et al. [51]. Pain was evaluated using VAS. Moreover, the number of analgesics consumed was also registered. Trismus was determined by measuring maximum interincisal opening. Assessment of facial swelling and trismus were obtained before surgical intervention and one, two and seven days after surgery. A total of five patients did not participate in the study follow-up period for unreported reason [31].

The main results are described below and summarized in Tables $4-6$.

\section{Quality assessment}

The quality of the included studies is summarized in Table 7. A low risk of bias was found in two studies $[\underline{30,35] . ~ U n c l e a r ~ r i s k ~ o f ~ b i a s ~ w a s ~ f o u n d ~ i n ~ f i v e ~ s t u d i e s, ~}$ since the randomization method was not described $[\underline{31-34}, \underline{36}]$.

\section{Outcome measures}

The result of each outcome measure is presented first and then a short summary is finally provided. All the reported numerical values are presented as mean values. Patient-related outcome measures were not reported in any of the included studies and therefore not described below or in Tables $4-6$. 
Table 5. Included studies assessing different administration routes of corticosteroids

\begin{tabular}{|c|c|c|c|c|c|c|c|c|c|c|c|c|c|c|}
\hline \multirow[b]{2}{*}{ Study } & \multirow{2}{*}{$\begin{array}{c}\text { Year of } \\
\text { publication }\end{array}$} & \multicolumn{3}{|c|}{ Patients } & \multicolumn{7}{|c|}{ Materials and methods } & \multicolumn{3}{|c|}{ Outcome measures } \\
\hline & & Number & $\begin{array}{c}\text { Age } \\
\text { (years) }\end{array}$ & Sex & & $\mathbf{N}$ & AT & $\mathbf{A R}$ & $\mathrm{CO}$ & DO & $\begin{array}{l}\text { DO in } \\
\text { DEX }\end{array}$ & Swelling & Pain & Trismus \\
\hline \multirow{2}{*}{ Boonsiriseth et al. [36] } & \multirow{2}{*}{2012} & \multirow{2}{*}{20} & \multirow{2}{*}{20} & \multirow{2}{*}{$\begin{array}{l}3 \mathrm{M} ; \\
17 \mathrm{~F}\end{array}$} & $\mathrm{~A}$ & 20 & \multirow{2}{*}{ POSTOP } & I.m. & \multirow{2}{*}{ DEX } & $8 \mathrm{mg}$ & $8 \mathrm{mg}$ & \multirow{2}{*}{-} & \multirow{2}{*}{ - } & \multirow{2}{*}{ - } \\
\hline & & & & & $\mathrm{B}$ & 20 & & Oral & & $8 \mathrm{mg}$ & $8 \mathrm{mg}$ & & & \\
\hline
\end{tabular}

$\mathrm{AR}=$ administration route; $\mathrm{AT}=$ administration time; $\mathrm{CO}=$ corticosteroid; $\mathrm{DEX}=$ dexamethasone; $\mathrm{DO}=$ dose; I.m. $=$ intramuscular; $\mathrm{N}=$ number of interventions; POSTOP = postoperatively; $\mathrm{M}=$ male; $\mathrm{F}=$ female.

Table 6. Included studies assessing different doses and administration routes of corticosteroids

\begin{tabular}{|c|c|c|c|c|c|c|c|c|c|c|c|c|c|c|}
\hline \multirow[b]{2}{*}{ Study } & \multirow{2}{*}{$\begin{array}{c}\text { Year of } \\
\text { publication }\end{array}$} & \multicolumn{3}{|c|}{ Patients } & \multicolumn{7}{|c|}{ Materials and methods } & \multicolumn{3}{|c|}{ Outcome measures } \\
\hline & & Number & $\begin{array}{c}\text { Age } \\
\text { (years) }\end{array}$ & Sex & & $\mathbf{N}$ & AT & $\mathbf{A R}$ & $\mathrm{CO}$ & DO & $\begin{array}{c}\text { DO in } \\
\text { DEX }\end{array}$ & Swelling & Pain & Trismus \\
\hline \multirow{2}{*}{ Chaudhary et al. [31] } & \multirow{2}{*}{2015} & \multirow{2}{*}{200} & \multirow{2}{*}{20.8} & \multirow{2}{*}{ NM } & $\mathrm{A}$ & 100 & \multirow{2}{*}{ PREOP } & i.v. & \multirow{2}{*}{ DEX } & $4 \mathrm{mg}$ & $4 \mathrm{mg}$ & \multirow{2}{*}{-} & \multirow{2}{*}{-} & \multirow[b]{2}{*}{ - } \\
\hline & & & & & $\mathrm{B}$ & 100 & & Oral & & $8 \mathrm{mg}$ & $8 \mathrm{mg}$ & & & \\
\hline \multirow{4}{*}{ Graziani et al. [35] } & \multirow{4}{*}{2006} & \multirow{4}{*}{43} & \multirow{4}{*}{$24(\mathrm{SD} 4)$} & \multirow{4}{*}{$\begin{array}{l}13 \mathrm{M} \\
30 \mathrm{~F}\end{array}$} & A & 15 & \multirow{4}{*}{ POSTOP } & E.a. & \multirow{4}{*}{ DEX } & $4 \mathrm{mg}$ & $4 \mathrm{mg}$ & \multirow{4}{*}{$\begin{array}{c}* \\
\mathrm{~A}, \mathrm{~B}, \\
\mathrm{C}<\mathrm{D}\end{array}$} & \multirow{4}{*}{$\begin{array}{c}* \\
\mathrm{~A}< \\
\mathrm{B}, \mathrm{C}, \mathrm{D}\end{array}$} & \multirow{4}{*}{$\begin{array}{c}* \\
\mathrm{~A}, \mathrm{~B}< \\
\mathrm{C}, \mathrm{D}\end{array}$} \\
\hline & & & & & $\mathrm{B}$ & 14 & & E.a. & & $10 \mathrm{mg}$ & $10 \mathrm{mg}$ & & & \\
\hline & & & & & $\mathrm{C}$ & 14 & & S.m. & & $4 \mathrm{mg}$ & $4 \mathrm{mg}$ & & & \\
\hline & & & & & $\mathrm{D}$ & 43 & & - & & $0 \mathrm{mg}$ & $0 \mathrm{mg}$ & & & \\
\hline
\end{tabular}

*Significant difference between groups, $\mathrm{P}<0.05$.

$\mathrm{AR}=$ administration route; $\mathrm{AT}=$ administration time; $\mathrm{CO}=$ corticosteroid; $\mathrm{DEX}=$ dexamethasone; $\mathrm{DO}=$ dose; E.a. $=$ endo-alveolar; i.v. = intravenous; $\mathrm{N}=$ number of interventions; $\mathrm{NM}=$ not mentioned; POSTOP = postoperatively; PREOP = preoperatively; S.m. = submucosal; $\mathrm{M}=$ male; $\mathrm{F}=$ female.

Table 7. Quality assessment of included studies using Cochrane Collaboration's tool [29]

\begin{tabular}{l|c|c|c|c|c|c|c|c}
\hline \multicolumn{1}{|c|}{ Study } & $\begin{array}{c}\text { Sequence } \\
\text { generation }\end{array}$ & $\begin{array}{c}\text { Allocation } \\
\text { concealment }\end{array}$ & $\begin{array}{c}\text { Blinding of } \\
\text { participants, } \\
\text { personnel }\end{array}$ & $\begin{array}{c}\text { Blinding of } \\
\text { outcome } \\
\text { assessors }\end{array}$ & $\begin{array}{c}\text { Incomplete } \\
\text { outcome } \\
\text { data }\end{array}$ & $\begin{array}{c}\text { Selective } \\
\text { outcome } \\
\text { reporting }\end{array}$ & $\begin{array}{c}\text { Other } \\
\text { sources of } \\
\text { bias }\end{array}$ & $\begin{array}{c}\text { Study } \\
\text { quality of } \\
\text { bias }\end{array}$ \\
\hline Lim and Ngeow [30] & Yes & Yes & Yes & Yes & Yes & Yes & Yes & Low risk \\
\hline Chaudhary et al. [31] & Unclear & Unclear & Yes & Yes & Yes & Yes & Yes & Unclear risk \\
\hline Üstün et al. [32] & Unclear & Unclear & Yes & Yes & Yes & Yes & Yes & Unclear risk \\
\hline Laureano Filho et al. [33] & Unclear & Unclear & Unclear & Yes & Yes & Yes & Yes & Unclear risk \\
\hline Agostinho et al. [34] & Unclear & Unclear & Yes & Yes & Yes & Yes & Yes & Unclear risk \\
\hline Graziani et al. [35] & Yes & Yes & Yes & Yes & Yes & Yes & Yes & Low risk \\
\hline Boonsiriseth et al. [36] & Unclear & Unclear & Yes & Yes & Yes & Yes & Yes & Unclear risk \\
\hline
\end{tabular}

The amount of facial swelling and trismus among the included studies is present in Figure 2 and 3.

\section{Facial swelling}

Different dosages of corticosteroids disclosed no significant differences in facial swelling at any time points after preoperative intravenous administration of $1.5 \mathrm{mg} / \mathrm{kg}$ methylprednisolone compared with $3 \mathrm{mg} / \mathrm{kg}$, submucosal injection of $40 \mathrm{mg}$ methylprednisolone compared with $4 \mathrm{mg}$ dexamethasone and oral consumption of $4 \mathrm{mg}$ dexamethasone compared with $12 \mathrm{mg}$, respectively $[\underline{30}, \underline{32}, \underline{34}]$. However, a significant diminished facial swelling was reported after oral consumption of $8 \mathrm{mg}$ dexamethasone compared with $4 \mathrm{mg}$, one and two days after surgery [33]. Moreover, submucosal injection of $40 \mathrm{mg}$ methylprednisolone or $4 \mathrm{mg}$ dexamethasone revealed significant diminished facial swelling compared with placebo [30].

Different administration routes of corticosteroids disclosed no significant differences in facial swelling at any time points after preoperative oral consumption of $8 \mathrm{mg}$ dexamethasone compared with intramuscular injection of $8 \mathrm{mg}$ dexamethasone [36].

Different dosages and administration routes of corticosteroids disclosed no significant differences in facial swelling at any time points after intravenous 


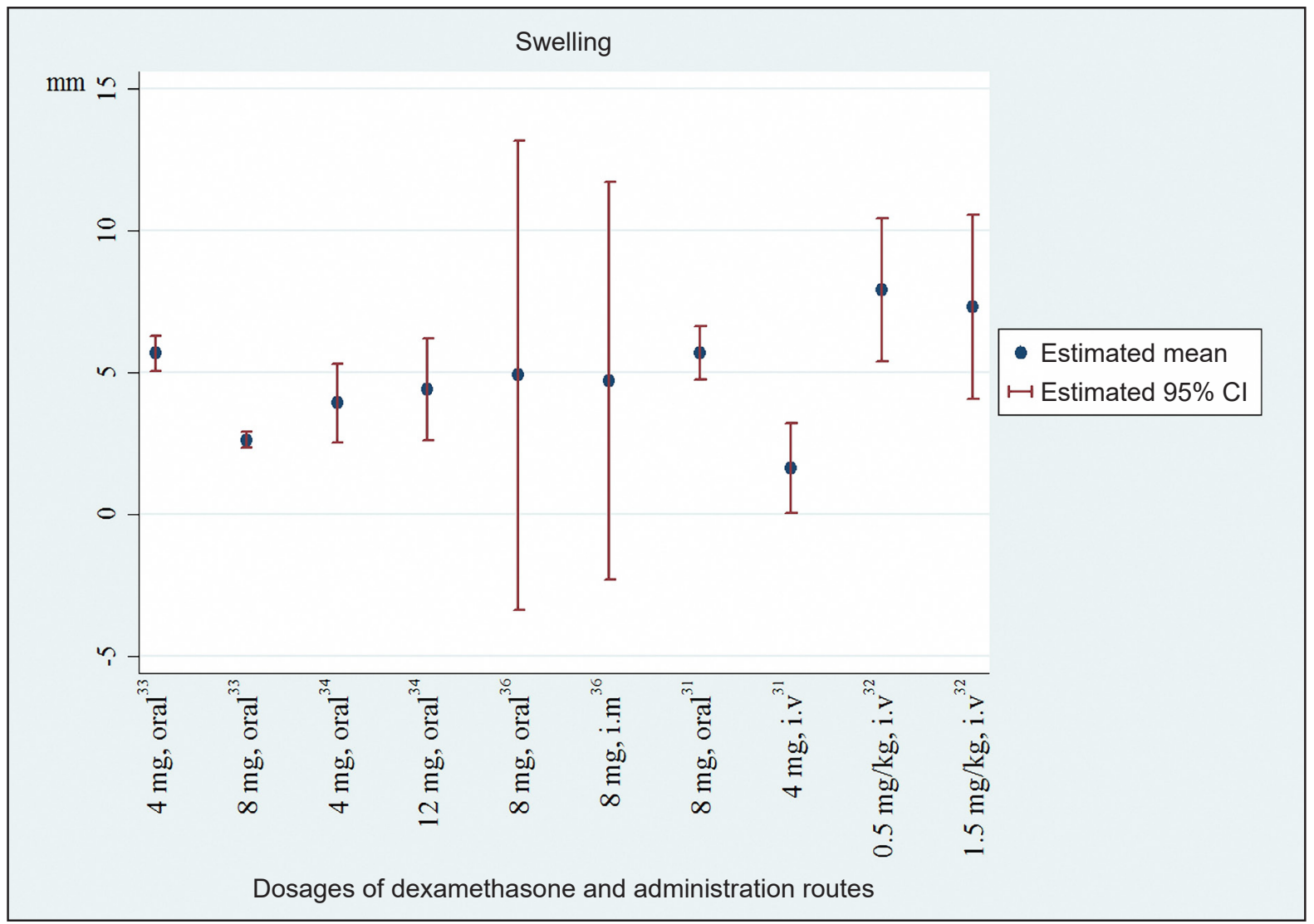

Figure 2. Facial swelling $(\mathrm{mm})$ with different dosages of dexamethasone and administration routes. $\mathrm{CI}=$ confidence interval; i.m. $=$ intramuscular; i.v. $=$ intravenous.

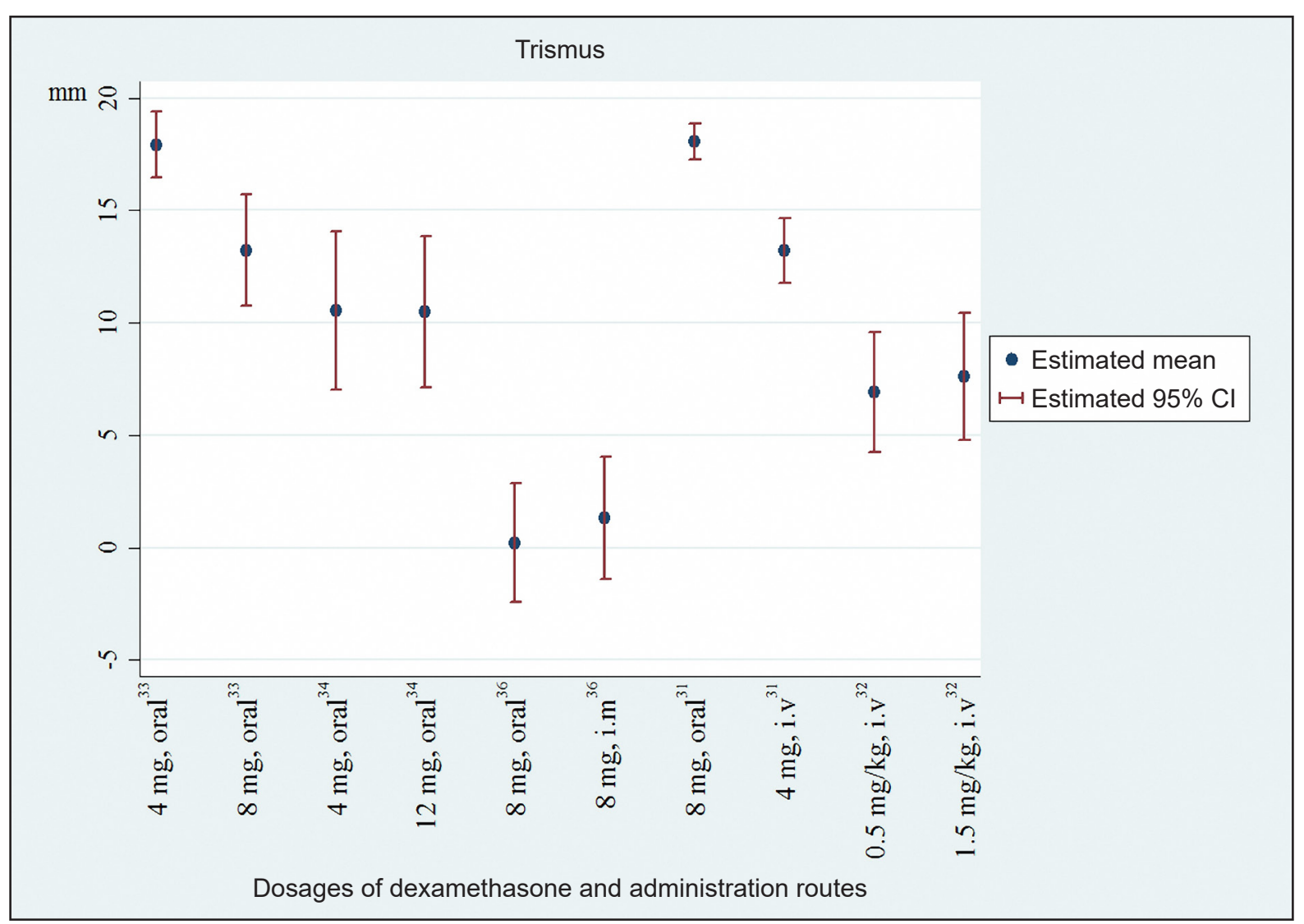

Figure 3. Trismus (mm) with different dosages of dexamethasone and administration routes. $\mathrm{CI}=$ confidence interval; i.m. $=$ intramuscular; i.v. $=$ intravenous . 
administration of $4 \mathrm{mg}$ dexamethasone compared with oral consumption of $8 \mathrm{mg}$ dexamethasone [31]. Endo-alveolar application of $4 \mathrm{mg}$ and 10 $\mathrm{mg}$ dexamethasone and submucosal injection of 4 $\mathrm{mg}$ dexamethasone significantly diminished facial swelling compared to placebo [35].

In summary, preoperative submucosal injection of corticosteroids seems to diminish facial swelling compared to placebo after surgical removal of impacted M3. However, there seems to be no difference in facial swelling with dissimilar dosage of corticosteroids or route of administration, although oral consumption of $8 \mathrm{mg}$ dexamethasone disclosed significant diminished facial swelling compared with $4 \mathrm{mg}$ during the first postoperative days [33]. The degree of facial swelling in the abovementioned studies is outlined in Figure 2.

\section{Pain}

Different dosages of corticosteroids disclosed no significant differences in pain at any time points after preoperative intravenous administration of $1.5 \mathrm{mg} /$ $\mathrm{kg}$ methylprednisolone compared with $3 \mathrm{mg} / \mathrm{kg}$, oral consumption of $4 \mathrm{mg}$ dexamethasone compared with $8 \mathrm{mg}$ and oral consumption of $4 \mathrm{mg}$ dexamethasone compared with $12 \mathrm{mg}$, respectively [32-34]. However, significant reduced pain was reported after submucosal injection of $40 \mathrm{mg}$ methylprednisolone compared with $4 \mathrm{mg}$ dexamethasone, one, two, five and seven days after surgery [30]. Moreover, submucosal injection of $40 \mathrm{mg}$ methylprednisolone or $4 \mathrm{mg}$ dexamethasone revealed significant diminished pain compared with placebo [30].

Different administration routes of corticosteroids disclosed no significant differences in pain at any time points after preoperative oral consumption of $8 \mathrm{mg}$ dexamethasone compared with intramuscular injection of $8 \mathrm{mg}$ dexamethasone [하].

Different dosages and administration routes of corticosteroids disclosed no significant differences in pain at any time points after intravenous administered of $4 \mathrm{mg}$ dexamethasone compared with oral consumption of $8 \mathrm{mg}$ dexamethasone [31]. However, endo-alveolar application of $4 \mathrm{mg}$ dexamethasone revealed significantly diminished pain compared with endo-alveolar application of $10 \mathrm{mg}$ dexamethasone or submucosal injection of $4 \mathrm{mg}$ dexamethasone, after two and seven days [35].

In summary, preoperative submucosal injection of corticosteroids seems to reduce postoperative pain compared with placebo after surgical removal of impacted M3. Moreover, endo-alveolar application of corticosteroids compared with submucosal injection seems to significantly diminish postsurgical pain. However, endo-alveolar application with a higher dosage of corticosteroids seems not to proportionally reduce pain after removal of impacted M3.

\section{Trismus}

Different dosages of corticosteroids disclosed no significant differences in trismus at any time points after preoperative intravenous administration of 1.5 $\mathrm{mg} / \mathrm{kg}$ methylprednisolone compared to $3 \mathrm{mg} / \mathrm{kg}$, submucosal injection of $40 \mathrm{mg}$ methylprednisolone compared to $4 \mathrm{mg}$ dexamethasone, and oral consumption of $4 \mathrm{mg}$ dexamethasone compared to $12 \mathrm{mg}$, respectively $[\underline{30}, \underline{32}, \underline{34}]$. However, a significant diminished trismus was reported after oral consumption of $8 \mathrm{mg}$ dexamethasone compared to 4 $\mathrm{mg}$, one and two days after surgery [33]. Moreover, submucosal injection of $40 \mathrm{mg}$ methylprednisolone or $4 \mathrm{mg}$ dexamethasone revealed significant diminished trismus compared to placebo [일.

Different administration routes of corticosteroids disclosed no significant differences in trismus at any time points after preoperative oral consumption of $8 \mathrm{mg}$ dexamethasone compared to intramuscular injection of $8 \mathrm{mg}$ dexamethasone [36].

Different dosages and administration routes of corticosteroids disclosed no significant differences in trismus at any time points after intravenous administered of $4 \mathrm{mg}$ dexamethasone compared to oral consumption of $8 \mathrm{mg}$ dexamethasone [35]. Endoalveolar application of $4 \mathrm{mg}$ dexamethasone or $10 \mathrm{mg}$ dexamethasone reveal significantly reduced trismus at any time points compared to submucosal injection of $4 \mathrm{mg}$ dexamethasone [31].

In summary, preoperative submucosal injection of corticosteroids seems to reduce postoperative trismus compared with placebo after surgical removal of impacted M3. Moreover, endo-alveolar application compared with submucosal injection seems to decrease trismus. However, the use of a higher dosage of corticosteroids seems not to proportionally diminish trismus after removal of impacted M3. The degree of trismus in the abovementioned studies is outlined in Figure 3.

\section{Complications}

Complications were not described in three studies $[31,33,36]$ and no complications were reported in two studies $[\underline{30}, \underline{35}]$. One study excluded patients with complications and did not describe the number or the degree of complications [34]. Mild nausea was described in one patient after six days [32]. 
In summary, complications related to preoperative administration of corticosteroids in conjunction with surgical removal of M3 seem to be negligible.

\section{DISCUSSION}

The objective of the present systematic review was to test the hypothesis of no difference in facial swelling, pain and trismus after surgical removal of impacted M3 with different dosages of corticosteroid and routes of administration. A total of seven RCT were included in the present systematic review [30-36]. Two studies were considered low risk of bias [30,35], whereas five studies were considered unclear risk of bias $[31-34,36]$. Preoperative submucosal injection of corticosteroids significantly diminishes facial swelling, pain and trismus compared with placebo [30]. However, different dosages of corticosteroid and routes of administration reveal contrary results indicating that administration of a higher dosage of corticosteroids do not necessarily cause a proportionally decrease in facial swelling, pain and trismus. Moreover, the included studies revealed considerable heterogeneity in patient demographic, study design as well as evaluation methods, outcome measures and posed various methodological confounding factors, which yield serious restrictions to review the literature in a quantitative systematic manner. Hence, the conclusions drawn from the results of this systematic review had to be cautiously interpreted.

Preoperative administration of corticosteroids significantly diminishes facial swelling compared with placebo after surgical removal of M3, which has previously been documented in systematic reviews and meta-analyses [21-23,25]. These results are in accordance with the results of the present systematic review. The included studies of the present systematic review used two-dimensional linear $[\underline{30}, \underline{32}, \underline{35}, \underline{36}]$ or angle $[\underline{31}, \underline{33}, \underline{34}]$ measurements for assessment of the postoperative facial swelling. The validity and reliability of quantifying volume changes in facial morphology by using two-dimensional imaging are limited and associated with significant ambiguity. Two-dimensional measurements lack appropriate facial depth and shape $[\underline{52}, \underline{53}]$. Threedimensional facial optical scanning technique improves measurement accuracy and has previously been used for assessment of facial swelling after surgical removal of impacted M3 using two different cooling therapy methods and low-level laser therapy, treatment of zygomatic fractures and in orthognathic surgery [54-58]. Moreover, a study with three- dimensional photogrammetry reported that $4 \mathrm{mg}$ dexamethasone significantly reduced facial swelling after surgical removal of mandibular M3 compared to placebo [59]. Conversely, a newly published RCT using three-dimensional photogrammetry demonstrated that $15 \mathrm{mg}$ dexamethasone did not further reduce postoperative facial swelling compared with $5 \mathrm{mg}$ in orthognathic surgery [24]. Hence, further RCT assessing the influence of corticosteroids on facial swelling after surgical removal of impacted M3 should include standardized three-dimensional facial scanning measurements.

Anti-inflammatory analgesic also reduces tissue swelling after surgical removal of M3. Dissimilar dosages and brands of postoperative analgesics were administered in the included studies, which presumably influence the degree of postoperative facial swelling [60]. Thus, further RCT assessing the influence of corticosteroids on postoperative facial swelling after surgical removal of M3 should include a standardized analgesics protocol.

Pain is the most common complication following surgical removal of M3, which may affect or impair the patient's immediate quality of life and habits. The pain relief effect of corticosteroids is presumably due to the inhibitory effect on prostaglandin formation and diminished postsurgical facial swelling [18]. Preoperative administration of corticosteroids significantly diminishes postoperative pain compared with placebo after surgical removal of impacted M3, which has been documented in systematic reviews and meta-analyses [21-23,25]. These results are in accordance with the results of the present systematic review. However, the reduction in pain with the use of corticosteroids disclosed contradictory results among the included studies of the present systematic review [30-36]. A significant improved pain relief was obtained with endo-alveolar application of corticosteroids compared with submucosal injection, whereas a higher dosage of corticosteroids seemed not to proportionally reduce pain after surgical removal of impacted M3. All of the included studies measured pain with VAS [30-36], which is one of the best known and commonly preferred scale to measure pain [61]. Other pain assessment methods as verbal rating scale and full cup test have also been used after surgical removal of M3 [61]. However, these assessment methods do not distinguish between pain tolerance or expectation []]. Furthermore, three studies measured pain with the consumption of analgesics $[\underline{30}, \underline{32}, \underline{34}]$. The type and dosage of analgesics varied between the studies. Two studies used paracetamol in different dosages $[\underline{32}, \underline{34}]$, and one study used mefanamic acid [30]. 
However, analgesics in regular dosages in the postoperative period were prescribed in three studies $[\underline{31}, \underline{33}, \underline{36}]$, and the use of postoperative analgesics was not described in one study [35]. Consequently, the reduction in pain can be related to the analgesics and not to the use of corticosteroids.

Pain assessment after surgical removal of impacted M3 may be influenced by objective and subjective factors including surgical trauma, duration of surgery and experience of the surgeon as well as anxiety, pain tolerance or pain expectation $[\underline{8}, \underline{62}]$. In addition, the sociocultural background may also have an effect on the pain level [63]. Standardization of the surgical technique, duration of the surgical procedure and experienced of the surgeon was described in some of the included studies of the present systematic review, whereas none of the included studies evaluated patients' anxiety, pain tolerance or expectation. Thus, further RCT assessing the influence of corticosteroids on pain after surgical removal of impacted M3 should include a standardized postoperative protocol and assessment of anxiety, pain tolerance or expectation.

Postsurgical trismus caused by facial swelling, pain, hematoma or inflammation may interfere with the patients' ability to eat, speak and maintaining proper oral hygiene. Preoperative administration of corticosteroids seems to reduce trismus compared with placebo after surgical removal of impacted M3, as documented in previous published systematic reviews and meta-analyses [21-23,25]. However, a newly published meta-analysis disclosed no significant difference in trismus between corticosteroids and placebo [26]. These conflicting results are in accordance with the results of the present systematic review. Mandibular range of motion is commonly measured with maximum opening, left lateral, right lateral and protrusive movement. Jaw range of motion scale, TheraBite ${ }^{\mathbb{B}}$ (Atos Medical, Hörby, Sweden) range of motion scale and interincisal maximal mouth opening are different measurement tools to determine opening, lateral and protrusive mandibular range of motion $[64,65]$. TheraBite $^{\circledR}$ range of motion scale is a reproducible and valid mouth opening measurement tool using a cardboard scale [65]. Linear measurements of interincisal maximal mouth opening before and after surgical removal of impacted M3 is a simple, reliable, reproducible and validated method for assessment of postsurgical trismus, which has been used in all of the included studies of the present systematic review.

Several factors may influence postoperative sequelae after surgical removal of impacted M3 including systemic medical conditions, smoking, oral hygiene, physical activity, surgical trauma, duration of surgery and experience of the surgeon $[\underline{6}, \underline{7}]$. A newly published retrospective study reported that dry socket was the most common complication after M3 extraction and the overall prevalence of postsurgical complications was $17 \%$ [66]. It has previously been documented in a retrospective study, that partially impacted teeth reveal the highest incidence of complications and cigarette smoking correlated with an increased complication rate and dry sockets [66]. The included studies of the present systematic review excluded medically compromised patients and smoking habits was not reported in any of the included studies [30-36]. However, the percentage of dry socket was not described in any of the included studies and complications were only reported in one study involving mild nausea [32].

Prolonged use of corticosteroids may interfere with the natural wound healing process and increase the risk of infection due to an inhibiting effect on the body's inflammatory response $[\underline{17}, \underline{18}]$. However, increased risk of postsurgical infection related to a single dosage of corticosteroid has never previously been reported and none of the included studies of the present systematic review described side effects related to the dosage of corticosteroids or the route of administration.

Patient-reported outcome measures are essentially subjective reports of patient perceptions of their oral health status and its impact on their daily life or quality of life. The Oral Health Impact Profile Questionnaire (OHIP), Orofacial Esthetic Scale and Chewing Function Questionnaire are standardised methods commonly used for the assessment of patient-reported outcome measures. Health-related quality of life measures are valid and reflect the severity of a disease and how it affects or impairs a patient's life. None of the included studies in the present systematic review used patient-reported outcome measures for assessment of the final treatment outcome. However, OHIP-14 and other questionnaires have previously been used to assess patient-reported outcome measures after surgical removal of impacted $\mathrm{M} 3$ revealing that administration of corticosteroids improve the immediate quality of life $[39, \underline{67}]$. A RCT showed that submucosal injection and oral consumption of prednisolone were associated with less deterioration in quality of life compared to placebo after surgical removal of M3 [39]. Furthermore, significantly better quality of life was seen in patients receiving prednisolone into submucosa compared to oral consumption [39]. Consequently, further RCT assessing the 
treatment outcome after surgical removal of M3 with administration of corticosteroids should include standardized patient-reported outcome measures.

Corticosteroids can be administered before, during or after surgical removal of M3. None of the included studies in the present systematic review focused on the time of administration. Five studies administered it preoperatively [30-34], whereas two studies administered it postoperatively $[\underline{35}, \underline{36}]$. Preoperatively administered methylprednisolone has previously shown deterioration in postoperative swelling, pain and trismus compared to postoperatively administered corticosteroid [68]. However, postoperatively administered dexamethasone has provided less postoperative pain compared to preoperative administration [69]. Consequently, further RCT assessing the treatment outcome after surgical removal of M3 with different time of administration of corticosteroids should be performed.

To summarise, preoperative administration of corticosteroids significantly reduces the degree of facial swelling, pain and trismus after surgical removal of impacted M3 $[\underline{22}, \underline{23}, \underline{25}, \underline{26}]$. From a clinical and patient perspective, it would be an advantage to use the least dose of corticosteroids and submucosal injection compared to other routes of administration. However, the optimal dosage and route of administration with the highest effect on facial swelling, pain and trismus is presently unknown. Moreover, preoperative administration of corticosteroids in mandibular M3 surgery should be individualized and only prescribed in cases where moderate postoperative pain and swelling is expected.

\section{CONCLUSIONS}

The hypothesis of no difference in facial swelling, pain or trismus after surgical removal of impacted mandibular third molar with different dosages of corticosteroids and routes of administration could neither be confirmed nor rejected due to insufficient knowledge. Preoperative submucosal injection of corticosteroids significantly diminishes facial swelling, pain and trismus compared with placebo. However, different dosages of corticosteroids and administration routes reveal contrary results indicating that administration of a higher dosage of corticosteroids do not necessarily cause a proportionally decrease in facial swelling, pain and trismus. Consequently, the optimal dosage of corticosteroids and administration route for diminishing postsurgical morbidity and improve the immediate quality of life after surgical removal of mandibular third molar is presently unknown. Therefore, further well-designed randomized clinical trials including a standardised protocol, larger patient sample, patient-reported outcome measures and threedimensional analysis of facial swelling is needed.

\section{ACKNOWLEDGMENTS AND DISCLOSURE STATEMENTS}

The authors report no conflicts of interest related to this study. We would like to give a special thanks to the librarian Marianne Buschmann Nielsen (Aalborg University Hospital, Aalborg, Denmark) for her assistance with the search strategy. There were no sources of funding for this systematic review.

\section{REFERENCES}

1. Coulthard P, Bailey E, Esposito M, Furness S, Renton TF, Worthington HV. Surgical techniques for the removal of mandibular wisdom teeth. Cochrane Database Syst Rev. 2014 Jul 29;(7):CD004345. [Medline: 25069437] [doi: 10.1002/14651858.CD004345.pub2]

2. Colorado-Bonnin M, Valmaseda-Castellón E, Berini-Aytés L, Gay-Escoda C. Quality of life following lower third molar removal. International Journal of Oral and Maxillofacial Surgery. 2006 Aug;35(4):343-7. [Medline: 16280233] [doi: 10.1016/j.ijom.2005.08.008]

3. Kawecki TJ, Ebert D. Conceptual issues in local adaptation. Ecology Letters. 2004 Jan;7(12):1225-41. [doi: 10.1111/j.1461-0248.2004.00684.x]

4. Negreiros RM, Biazevic MGH, Jorge WA, Michel-Crosato E. Relationship between oral health-related quality of life and the position of the lower third molar: Postoperative follow-up. Journal of Oral and Maxillofacial Surgery. 2012 Aug;70(4):779-86. [Medline: 22177812] [doi: 10.1016/j.joms.2011.09.034]

5. McGrath C, Comfort MB, Lo ECM, Luo Y. Changes in life quality following third molar surgery-the immediate postoperative period. British Dental Journal. 2003 Feb;194(1):265-8; discussion 261. [Medline: 12658303] [doi: $10.1038 /$ sj.bdj.4809930]

6. Baqain ZH, Karaky AA, Sawair F, Khraisat A, Duaibis R, Rajab LD. Frequency estimates and risk factors for postoperative morbidity after third molar removal: a prospective cohort study. J Oral Maxillofac Surg. 2008 Nov;66(11):2276-83. [Medline: 18940492] [doi: 10.1016/j.joms.2008.06.047] 
7. Monaco G, De Santis G, Pulpito G, Gatto MRA, Vignudelli E, Marchetti C. What Are the Types and Frequencies of Complications Associated With Mandibular Third Molar Coronectomy? A Follow-Up Study. Journal of Oral and Maxillofacial Surgery: Official Journal of the American Association of Oral and Maxillofacial Surgeons. 2015 Jul;73(7):1246-53. [Medline: 25914134] [doi: 10.1016/j.joms.2015.01.016]

8. Wang T, Wu Y, Tseng C, Chou C. Associations between dental anxiety and postoperative pain following extraction of horizontally impacted wisdom teeth: A prospective observational study. Medicine. 2017 Nov;96(47):8665. [Medline: 29381942] [doi: 10.1097/MD.0000000000008665]

9. Zandi M, Amini P, Keshavarz A. Effectiveness of cold therapy in reducing pain, trismus, and oedema after impacted mandibular third molar surgery: a randomized, self-controlled, observer-blind, split-mouth clinical trial. International Journal of Oral and Maxillofacial Surgery. 2016;45:118-23. [Medline: 26597577] [doi: 10.1016/j.ijom.2015.10.021]

10. Zandi M, Amini P, Keshavarz A. Effectiveness of cold therapy in reducing pain, trismus, and oedema after impacted mandibular third molar surgery: a randomized, self-controlled, observer-blind, split-mouth clinical trial. International Journal of Oral and Maxillofacial Surgery. 2016 Jan;45(1):118-23. [Medline: 26597577] [doi: 10.1016/j.ijom.2015.10.021]

11. Rullo R, Addabbo F, Papaccio G, D’Aquino R, Festa VM. Piezoelectric device vs. conventional rotative instruments in impacted third molar surgery: relationships between surgical difficulty and postoperative pain with histological evaluations. Journal of Cranio-Maxillo-Facial Surgery : Official Publication of the European Association for CranioMaxillo-Facial Surgery. 2013 Mar;41(2):33-8. [Medline: 22890087] [doi: 10.1016/j.jcms.2012.07.007]

12. Atkinson HC, Currie J, Moodie J, Carson S, Evans S, Worthington JP, Steenberg LJ, Bisley E, Frampton C. Combination paracetamol and ibuprofen for pain relief after oral surgery: a dose ranging study. Eur J Clin Pharmacol. 2015 May;71(5):579-87. [Medline: 25778933] [doi: 10.1007/s00228-015-1827-x]

13. Juhl GI, Norholt SE, Tonnesen E, Hiesse-Provost O, Jensen TS. Analgesic efficacy and safety of intravenous paracetamol (acetaminophen) administered as a $2 \mathrm{~g}$ starting dose following third molar surgery. European Journal of Pain. 2006 May;10(4):371-7. [Medline: 16085437] [doi: 10.1016/j.ejpain.2005.06.004]

14. Christensen J, Matzen LH, Schou S, Væth M, Wenzel A. Is thermography useful for assessment of postoperative inflammation after surgical removal of mandibular third molars when methylprednisolone is administered and how does it correlate with patients' perception of swelling? Journal of Oral and Maxillofacial Surgery. 2014 Mar;72(3):463-9. [Medline: 24315312] [doi: 10.1016/j.joms.2013.09.035]

15. Koçer G, Yuce E, Tuzuner Oncul A, Dereci O, Koskan O. Effect of the route of administration of methylprednisolone on oedema and trismus in impacted lower third molar surgery. International Journal of Oral and Maxillofacial Surgery. 2014 May;43(5):639-43. [Medline: 24332587] [doi: 10.1016/j.ijom.2013.11.005]

16. Goodman LS, Gilman A. Goodman \& Gilman's The Pharmacological Basis of Therapeutics, 11th Edition. Tuberculosis drugs, 2005, p. 1203-23.

17. Simon P. Skin wound healing. In: Meyers D, editor. eMedicine: Medscape. WebMD LLC, New York; 2016. [URL: https://emedicine.medscape.com/article/884594-overview]

18. Schleimer RP. An overview of glucocorticoid anti-inflammatory actions. European Journal of Clinical Pharmacology. 1993;45(1):3-7-4. [Medline: 8313932]

19. Hong SL, Levine L. Inhibition of arachidonic acid release from cells as the biochemical action of anti-inflammatory corticosteroids. Proceedings of the National Academy of Sciences of the United States of America. 1976 May;73(5): 1730-4. [Medline: 1064044] [doi: 10.1073/pnas.73.5.1730]

20. Hargreaves KM, Costello A. Glucocorticoids suppress levels of immunoreactive bradykinin in inflamed tissue as evaluated by microdialysis probes. Clinical Pharmacology and Therapeutics. 1990 Aug;48(2):168-78. [Medline: 2379387] [doi: $10.1038 /$ clpt.1990.132]

21. Ngeow WC, Lim D. Do Corticosteroids Still Have a Role in the Management of Third Molar Surgery? Advances in Therapy. 2016 Jul;33(7):1105-39. [Medline: 27287853] [doi:10.1007/s12325-016-0357-y]

22. Markiewicz MR, Brady MF, Ding EL, Dodson TB. Corticosteroids reduce postoperative morbidity after third molar surgery: a systematic review and meta-analysis. Journal of Oral and Maxillofacial Surgery : Official Journal of the American Association of Oral and Maxillofacial Surgeons. 2008 Sep;66(9):1881-94. [Medline: 18718396] [doi: 10.1016/i.joms.2008.04.022]

23. Dan AEB, Thygesen TH, Pinholt EM. Corticosteroid administration in oral and orthognathic surgery: a systematic review of the literature and meta-analysis. Journal of Oral and Maxillofacial Surgery : Official Journal of the American Association of Oral and Maxillofacial Surgeons. 2010 Sep;68(9):2207-20. [Medline: 20591548] [doi: 10.1016/i.joms.2010.04.019]

24. Lin HH, Kim SG, Kim HY, Niu LS, Lo LJ. Higher Dose of Dexamethasone Does Not Further Reduce Facial Swelling After Orthognathic Surgery: A Randomized Controlled Trial Using 3-Dimensional Photogrammetry. Annals of Plastic Surgery. 2017 Mar;78(3):61-9. [Medline: 28118231] [doi: 10.1097/SAP.0000000000001008]

25. Herrera-Briones FJ, Prados Sánchez E, Reyes Botella C, Vallecillo Capilla M. Update on the use of corticosteroids in third molar surgery: systematic review of the literature. Oral Surgery, Oral Medicine, Oral Pathology and Oral Radiology. 2013 Nov;116(5):342-51. [Medline: 22902498] [doi: 10.1016/j.0000.2012.02.027]

26. Moraschini V, Hidalgo R, Porto Barboza E dS. Effect of submucosal injection of dexamethasone after third molar surgery: a meta-analysis of randomized controlled trials. International Journal of Oral and Maxillofacial Surgery. 2016 Feb;45(2):232-40. [Medline: 26458538] [doi: 10.1016/j.ijom.2015.09.008] 
27. Jean S, Dionne PL, Bouchard C, Giasson L, Turgeon AF. Perioperative Systemic Corticosteroids in Orthognathic Surgery: A Systematic Review and Meta-Analysis. Journal of Oral and Maxillofacial Surgery : Official Journal of the American Association of Oral and Maxillofacial Surgeons. 2017 Dec;75(12):2638-49. [Medline: 28732219] [doi: 10.1016/j.joms.2017.06.014]

28. Welch V, Petticrew M, Petkovic J, Moher D, Waters E, White H, Tugwell P; PRISMA-Equity Bellagio group. Extending the PRISMA statement to equity-focused systematic reviews (PRISMA-E 2012): explanation and elaboration. Int J Equity Health. 2015 Oct 8;14:92. [Medline: 26450828] [PMC free article: 4599721] [doi: 10.1016/j.jclinepi.2015.09.001]

29. Higgins JPT, Green S.Cochrane Handbook for Systematic Reviews of Interventions. Version 5.1.0 [updated March 2011]. The Cochrane Collaboration, 2011. [URL: www.handbook.cochrane.org]

30. Lim D, Ngeow WC. A Comparative Study on the Efficacy of Submucosal Injection of Dexamethasone Versus Methylprednisolone in Reducing Postoperative Sequelae After Third Molar Surgery. Journal of Oral and Maxillofacial Surgery : Official Journal of the American Association of Oral and Maxillofacial Surgeons. 2017 Nov;75(11):2278-86. [Medline: 28666096] [doi: 10.1016/j.joms.2017.05.033]

31. Chaudhary PD, Rastogi S, Gupta P, Niranjanaprasad Indra B, Thomas R, Choudhury R. Pre-emptive effect of dexamethasone injection and consumption on post-operative swelling, pain, and trismus after third molar surgery. A prospective, double blind and randomized study. Journal of Oral Biology and Craniofacial Research. 2015;5(1):21-7. [Medline: 25853044] [doi: 10.1016/j.jobcr.2015.02.001]

32. Üstün Y, Erdoğan O, Esen E, Karsli ED. Comparison of the effects of 2 doses of methylprednisolone on pain, swelling, and trismus after third molar surgery. Oral Surgery, Oral Medicine, Oral Pathology, Oral Radiology, and Endodontics. 2003 Nov;96(5):535-9. [Medline: 18223530] [doi: 10.1016/S1079210403004645]

33. Laureano Filho JR, Maurette PE, Allais M, Cotinho M, Fernandes C. Clinical comparative study of the effectiveness of two dosages of Dexamethasone to control postoperative swelling, trismus and pain after the surgical extraction of mandibular impacted third molars. Medicina Oral, Patologia Oral Y Cirugia Bucal. 2008 Nov;13(2):129-32. [Medline: $\underline{18223530]}$

34. Agostinho CNLF, da Silva VC, Maia Filho EM, Cruz ML, Bastos EG. The efficacy of 2 different doses of dexamethasone to control postoperative swelling, trismus, and pain after third molar extractions. General Dentistry. 2014;62(6):1-5. [Medline: 25369393]

35. Graziani F, D’Aiuto F, Arduino PG, Tonelli M, Gabriele M. Perioperative dexamethasone reduces post-surgical sequelae of wisdom tooth removal. A split-mouth randomized double-masked clinical trial. International Journal of Oral and Maxillofacial Surgery. 2006 Mar;35(3):241-6. [Medline: 16188428] [doi: 10.1016/j.ijom.2005.07.010]

36. Boonsiriseth K, Klongnoi B, Sirintawat N, Saengsirinavin C, Wongsirichat N. Comparative study of the effect of dexamethasone injection and consumption in lower third molar surgery. International Journal of Oral and Maxillofacial Surgery. 2012 Feb;41(2):244-7. [Medline: 22209180] [doi: 10.1016/j.ijom.2011.12.011]

37. Antunes AA, Avelar RL, Martins Neto EC, Frota R, Dias E. Effect of two routes of administration of dexamethasone on pain, edema, and trismus in impacted lower third molar surgery. Oral and Maxillofacial Surgery. 2011 Dec;15(4):217-23. [Medline: 21845387] [doi: 10.1007/s10006-011-0290-9]

38. Darawade DA, Kumar S, Mehta R, Sharma AR, Reddy GS. In search of a better option: dexamethasone versus methylprednisolone in third molar impaction surgery. Journal of International Oral Health. 2014;6(6):14-7. [Medline: 25628476]

39. Ibikunle AA, Adeyemo WL, Ladeinde AL. Oral health-related quality of life following third molar surgery with either oral administration or submucosal injection of prednisolone. Oral and Maxillofacial Surgery. 2016 Dec;20(4):343-52. [Medline: 27447802] [doi: 10.1007/s10006-016-0571-4]

40. Ibikunle AA, Adeyemo WL, Ladeinde AL. Effect of submucosal or oral administration of prednisolone on postoperative sequelae following surgical extraction of impacted mandibular third molar: A randomized controlled study. Nigerian Medical Journal: Journal of the Nigeria Medical Association. 2016;57(5):272-9. [Medline: 27833246] [doi: 10.4103/0300-1652.190599]

41. Kang S-H, Choi Y-S, Byun I-Y, Kim M-K. Effect of preoperative prednisolone on clinical postoperative symptoms after surgical extractions of mandibular third molars. Australian Dental Journal. 2010 Dec;55(4):462-7. [Medline: 21174921] [doi: $10.1111 / \mathrm{j} .1834-7819.2010 .01271 . x]$

42. Pappalardo S, Puzzo S, Cappello V, Mastrangelo F, Adamo G, Caraffa A, Tetè S. The efficacy of four ways of administrating dexamethasone during surgical extraction of partially impacted lower third molars. European Journal of Inflammation. 2007 Oct;5(3):151-8. [doi: 10.1177/1721727X0700500306]

43. Rauf MA. The benefits of steroids therapy in surgical extraction of Mandibular third molar. Pakistan Journal of Medical and Health Sciences. 2015;9 (3):1019-20.

44. Saravanan K, Kannan R, John RR, Nantha Kumar C. A Single Pre Operative Dose of Sub Mucosal Dexamethasone is Effective in Improving Post Operative Quality of Life in the Surgical Management of Impacted Third Molars: A Comparative Randomised Prospective Study. Journal of Maxillofacial and Oral Surgery. 2016 Mar;15(1):67-71. [Medline: 26929555] [doi: 10.1007/s12663-015-0795-0] 
45. Grossi GB, Maiorana C, Garramone RA, Borgonovo A, Creminelli L, Santoro F. Assessing postoperative discomfort after third molar surgery: a prospective study. Journal of Oral and Maxillofacial Surgery: Official Journal of the American Association of Oral and Maxillofacial Surgeons. 2007 May;65(5):901-17. [Medline: 17448840] [doi: 10.1016/i.joms.2005.12.046]

46. Alcântara CEP, Falci SGM, Oliveira-Ferreira F, Santos CRR, Pinheiro MLP. Pre-emptive effect of dexamethasone and methylprednisolone on pain, swelling, and trismus after third molar surgery: a split-mouth randomized tripleblind clinical trial. International Journal of Oral and Maxillofacial Surgery. 2014 Jan;43(1):93-8. [Medline: 23810681] [doi: 10.1016/j.ijom.2013.05.016]

47. Sabhlok S, Kenjale P, Mony D, Khatri I, Kumar P. Randomized Controlled Trial to Evaluate the Efficacy of Oral Dexamethasone and Intramuscular Dexamethasone in Mandibular Third Molar Surgeries. Journal of Clinical and Diagnostic Research. 2015 Nov;9(11): 48-51. [Medline: 26675081] [doi: 10.7860/JCDR/2015/13930.6813]

48. Gabka J, Matsumura T. Measuring techniques and clinical testing of an anti-inflammatory agent (tantum). Munch Med Wochenschr. 1971;5(113):198-203.

49. Winter GB. Principles of exodontia as applied to the impacted mandibular third molar; a complete treatise on the operative technic with clinical diagnoses and radiographic interpretations. St. Louis, Mo.: American medical Book Company; 1926.

50. Pell G, Gregory G. The radiological assessment of ectopic lower third molars. The Dental Digestive. 1933;39(2):330. [Medline: 434748 ]

51. Neupert EA, Lee JW, Philput CB, Gordon JR. Evaluation of dexamethasone for reduction of postsurgical sequelae of third molar removal. Journal of Oral and Maxillofacial Surgery. 1992 Nov;50(11):1177-83. [Medline: 1403273] [doi: 10.1016/0278-2391(92)90149-T]

52. Honrado CP, Larrabee WF. Update in three-dimensional imaging in facial plastic surgery. Current Opinion in Otolaryngology \& Head and Neck Surgery. 2004;12(4):327-31. [Medline: 15252256] [doi: 10.1097/01.moo.0000130578.12441.99]

53. Da Silveira AC, Daw JL, Kusnoto B, Evans C, Cohen M. Craniofacial applications of three-dimensional laser surface scanning. The Journal of Craniofacial Surgery. 2003 Jul;14(4):449-56. [Medline: 12867855] [doi: 10.1097/00001665-200307000-00009]

54. Rana M, Gellrich NC, Ghassemi A, Gerressen M, Riediger D, Modabber A. Three-dimensional evaluation of postoperative swelling after third molar surgery using 2 different cooling therapy methods: a randomized observerblind prospective study. Journal of Oral and Maxillofacial Surgery. 2011 Aug;69(8):2092-8. [Medline: 21496998] [doi: 10.1016/j.joms.2010.12.038]

55. Kau CH, Cronin AJ, Richmond S. A three-dimensional evaluation of postoperative swelling following orthognathic surgery at 6 months. Plastic and Reconstructive Surgery. 2007 Sep;119(7):2192-9. [Medline: 17519721] [doi: 10.1097/01.prs.0000260707.99001.79]

56. van der Vlis M, Dentino KM, Vervloet B, Padwa BL. Postoperative swelling after orthognathic surgery: a prospective volumetric analysis. Journal of Oral and Maxillofacial Surgery: Official Journal of the American Association of Oral and Maxillofacial Surgeons. 2014 Nov;72(11):2241-7. [Medline: 25236819] [doi: 10.1016/j.joms.2014.04.026]

57. Alan H, Yolcu Ü, Koparal M, Özgür C, Öztürk SA, Malkoç S. Evaluation of the effects of the low-level laser therapy on swelling, pain, and trismus after removal of impacted lower third molar. Head \& Face Medicine. 2016 Jul;12(1):25. [Medline: 27457369] [doi: 10.1186/s13005-016-0121-1]

58. Li P, Zhou ZW, Ren JY, Zhang Y, Tian WD, Tang W. Accuracy of three-dimensional facial soft tissue simulation in posttraumatic zygoma reconstruction. International Journal of Oral and Maxillofacial Surgery. 2016 Dec;45(12):1665-70. [Medline: 27481688] [doi: 10.1016/j.ijom.2016.06.021]

59. Matsuda M, Kondo S, Seto M, Kita R, Mori H, Moriyama S. Three-Dimensional Quantitative Evaluation of the Effect of Local Administration of Dexamethasone on Facial Swelling after Impacted Mandibular Third Molar Extraction. J Dent \& Oral Disord J Dent \& Oral Disord. 2016 Sep;7(2). [URL: http://austinpublishinggroup.com/dental-disorders/fulltext/jdod-v2-id1036.php]

60. Sveen K, Gilhuus-Moe O. Paracetamol/codeine in relieving pain following removal of impacted mandibular third molars. International Journal of Oral Surgery. 1975 Dec;4(6):258-66. [Medline: 815188] [doi: 10.1016/S0300-9785(75)80043-3]

61. Isik K, Unsal A, Kalayci A, Durmus E. Comparison of three pain scales after impacted third molar surgery. Oral Surgery, Oral Medicine, Oral Pathology, Oral Radiology and Endodontology. 2011 Jan;112(6):715-8. [Medline: 21441046] [doi: 10.1016/j.tripleo.2011.01.001]

62. Mobilio N, Gremigni P, Pramstraller M, Vecchiatini R, Calura G, Catapano S. Explaining pain after lower third molar extraction by preoperative pain assessment. Journal of Oral and Maxillofacial Surgery : Official Journal of the American Association of Oral and Maxillofacial Surgeons. 2011 Nov;69(11):2731-8. [Medline: 21835529] [doi: 10.1016/j. joms.2011.05.023]

63. Aziato L, Adejumo O. An ethnographic exploration of postoperative pain experiences among Ghanaian surgical patients. J Transcult Nurs. 2015 May;26(3):301-7. [Medline: 24797253] [doi: 10.1177/1043659614526246]

64. Sahin SH, Yilmaz A, Gunday I, Kargi M, Sut N, Taskinalp O, Ulucam E. Using temporomandibular joint mobility to predict difficult tracheal intubation. J Anesth. 2011 Jun;25(3):457-61. [Medline: 21451975] [doi: 10.1007/s00540-011-1126-3] 
65. Saund DSS, Pearson D, Dietrich T. Reliability and validity of self-assessment of mouth opening: A validation study. BMC Oral Health. 2012;12:48-51. [Medline: 23145559] [doi: 10.1186/1472-6831-12-48]

66. Schwartz-Arad D, Lipovsky A, Pardo M, Adut O, Dolev E. Interpretations of complications following third molar extraction. Quintessence International. 2017 Nov;41:41-7. [Medline: 29164184] [doi: 10.3290/j.qi.a39334]

67. Majid OW. Submucosal dexamethasone injection improves quality of life measures after third molar surgery: a comparative study. Journal of Oral and Maxillofacial Surgery: Official Journal of the American Association of Oral and Maxillofacial Surgeons. 2011 Sep;69(9):2289-97. [Medline: 21514710] [doi: 10.1016/j.joms.2011.01.037]

68. Vyas N, Agarwal S, Shah N, Patel D, Aapaliya P. Effect of single dose intramuscular methylprednisolone injection into the masseter muscle on the surgical extraction of impacted lower third molars: a randomized controlled trial. Kathmandu Univ Med J (KUMJ). 2014 Jan-Mar;12(45):4-8. [Medline: 25219986]

69. Mojsa IM, Pokrowiecki R, Lipczynski K, Czerwonka D, Szczeklik K, Zaleska M. Effect of submucosal dexamethasone injection on postoperative pain, oedema, and trismus following mandibular third molar surgery: a prospective, randomized, double-blind clinical trial. International Journal of Oral and Maxillofacial Surgery. 2017 Apr;46(4):524-30. [Medline: 28012633] [doi: 10.1016/j.ijom.2016.11.006]

\section{To cite this article:}

Larsen MK, Kofod T, Christiansen AE, Starch-Jensen T.

Different Dosages of Corticosteroid and Routes of Administration in Mandibular Third Molar Surgery: a Systematic Review J Oral Maxillofac Res 2018;9(2):e1

URL: http://www.ejomr.org/JOMR/archives/2018/2/e1/v9n2e1.pdf

doi: $10.5037 /$ jomr.2018.9201

Copyright (C) Larsen MK, Kofod T, Christiansen AE, Starch-Jensen T. Published in the JOURNAL OF ORAL \& MAXILLOFACIAL RESEARCH (http://www.ejomr.org), 29 June 2018.

This is an open-access article, first published in the JOURNAL OF ORAL \& MAXILLOFACIAL RESEARCH, distributed under the terms of the Creative Commons Attribution-Noncommercial-No Derivative Works 3.0 Unported License, which permits unrestricted non-commercial use, distribution, and reproduction in any medium, provided the original work and is properly cited. The copyright, license information and link to the original publication on (http://www.ejomr.org) must be included. 


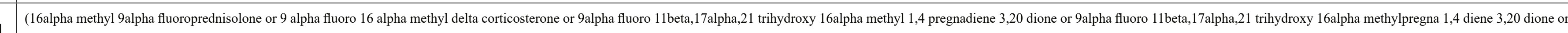
9alpha fluoro 16alpha methyl delta corticosterone).mp.

2 exp Adrenal Cortex Hormones/

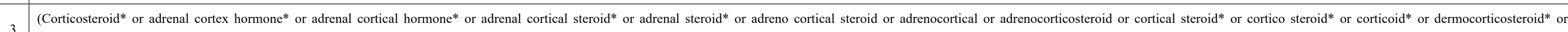
hydroxycorticosteroid* or glucocorticoid* or glucocorticosteroid or glucocorticoidsteroid or glucocortoid* or glycocorticoid or glycocorticosteroid).mp.

4 exp dexamethasone/

5 (Dexamethasone* or fluoroprednisolone or corticosterone or adrecort or adrenocot or aeroseb dex or aflucoson* or alfalyl or anaflogistico or arcodexan* or artrosone or azium or bidexol).mp.

6 exp methylprednisolone/

(methylprednisolone or 6 methyl delta 1 hydrocortisone or 6 methyl prednisolone or 6 methylprednisolone or 6alpha methyl deltal hydrocortisone or adlone-40 or adlone 80 or adlone-80 or adlone 40 or depmedalone or dep medalone or depoject-80 or depoject 80 or depopred

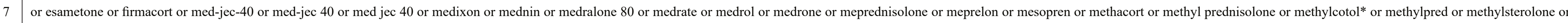
metidrol or metrisone or metycortin or metypred or metypresol or neomedrone or nsc 19987 or nsc 19987 or prednol or solomet or solu decortin or urbason).mp.

(Dexamethasone* or adrecort or adrenocot or aeroseb dex or aflucoson* or alfalyl or anaflogistico or arcodexan* or artrosone or azium or bidexol or calonat or cebedex or cetadexon or colofoam or corsona* or cortastat or cortidex* or cortisumman or cortidron* or dacortina fuerte or dacortine fuerte or dalalone or danasone or de-sone la or decacortin or decadeltoson* or decaderm or decadion or decadran or decadron* decaesadril or decaject or decameth* or decasone or decaspray or decasterolone or decdan or decilone or decoffluor* or dectancyl or dekacort or delladec or deltafluoren* or dergramin or deronil or desacort or desacortone or desalark or desameton* or desigdron or dexa cortisyl or dexa dabrosan or dexa korti or dexa scherosan or dexa scherozon or dexa-pdexa-p or dexacort* or dexacortin or dexacortin or dexadabroson

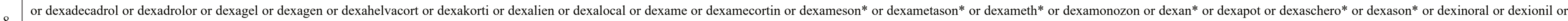

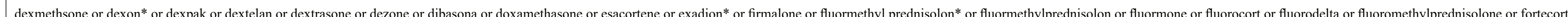
or gammacorten* or grosodexon* or hexadecadiol or hexadecadrol or hexadiol or hexadrol or isnacort or isopto dex or isopto maxidex or isoptodex or isoptomaxidex or lokalison for loverine or luxazone or marvidione or maxidex or mediamethasone or megacortin or mephameson * or metasolon* or methazon* ion or methazonion* or metisone lafi or mexasone or millicorten* or mk 125 or mymethasone or neoforde* or nisomethasona or novocort or nsc 34521 or nsc 34521 or oftan-dexa or opticort* or oradex* or orgadrone or ozurdex or pidexon or policort or posurdex or predni for prednisolone for prodexona or prodexone or sanamethasone or santenson or santeson or sawasone or solurex or spoloven or sterasone or thilodexine or triamcimetil or vexamet or visumetazone or visumethazone).mp.

9 exp prednisolone

(prednisolone or pregnadien* or adelcort or antisolon or antisolone or aprednislon or aprednislone or benisolon or benisolone or berisolon or berisolone or caberdelta or capsoid or co-hydeltra or co hydeltra or codelcortone or compresolon or cortadeltona or cortadeltone or cortalone or cortelinter or cortisolone or cotolone or dacortin or dacrotin or decaprednil or decorti* or dehydro cortex or dehydro hydrocortison* or dehydrocortex or dehydrocortisol or dehydrocortisole or dehydrohydrocortison or dehydrohydrocortisone or delcortol or hydroxycorticosterone or hydrocortisone or delta cortef or delta cortril or delta ef cortelan or delta hycortol or delta hydrocortison* or delta ophticor or delta stab or deltal dehydrocortisol* or deltal hydrocortisone or deltacortef or deltacortenolo or deltacortil or deltacortoil or deltacortril or deltaderm or deltaglycortril or deltahycortol or deltahydrocortison* or deltaophticor or deltasolone or deltastab or deltidrosol or deltisilone or deltisolon* or deltolasson* or deltosona or deltosone or depo-predate or depo predate or dermosolon* or di adreson f or diadreson f or di adresone f or

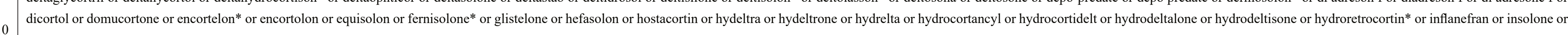

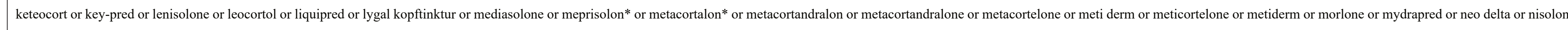
or nisolone or nsc 9120 or nsc 9120 or opredsone or panafcortelone or panafcortolone or panafort or paracortol or phlogex or pre cortisyl or preconin or precortalon or precortancyl or precortisyl or pred-ject-50 or pred ject 50 or predacort or predaject or predalone or predartrina or predartrine or predate or predeltilone or predisole or predisyr or predne dome or prednecort or prednedome or prednelan or predni coelin or predni h tablinen or predni-helvacort or predni helvacort or prednicoelin or prednicort* or prednifor or predniment or predniretard or prednis* or prednivet or prednorsolon* or predonine or predorgasolon* or prelon or prelone or prenilone or prenin or prenolone or preventan or prezolon or rubycort or scherisolon or scherisolona or serilone or solondo or solone or solupren or soluprene or spiricort or spolotane or sterane or sterolone or supercortisol or supercortizol or taracortelone or walesolone or wysolone).mp.

\section{1 exp betamethasone/}

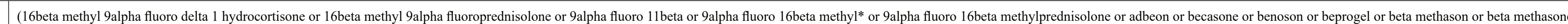

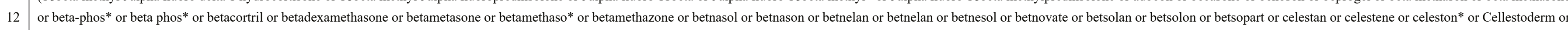
cidoten or dermobet or diprolen or flubenisolone or methasone or nsc 39470 or nsc 39470 or prednisolone or pregna $1 *$ or $\mathrm{rg} 833$ or rg 833 or rinderon or sch 4831 or sch 4831 or walacort).mp.

13 (third Molar* or Wisdom Tooth or Wisdom Teeth).mp.

14 exp Molar, Third/

\begin{tabular}{l|l|l}
15 & 13 or 14 \\
\hline 16 & or $1-12$
\end{tabular}

\begin{tabular}{l|l}
\hline 16 & or/1-12 \\
\hline 17 & 15
\end{tabular}

\begin{tabular}{l|l}
17 & 15 and 16 \\
\hline 18 &
\end{tabular}

\begin{tabular}{l|l}
\hline 18 & remove duplicates from 17 \\
\hline
\end{tabular} 
Appendix 2. Embase search until the $1^{\text {st }}$ of December 2017

ID

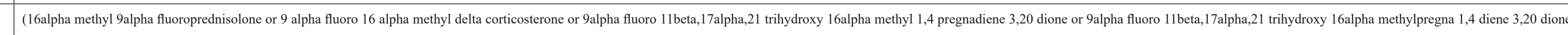
or 9alpha fluoro 16alpha methyl delta corticosterone).mp.

2 exp corticosteroid/

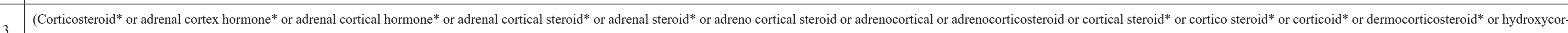
ticosteroid* or glucocorticoid* or glucocorticosteroid or glucocorticoidsteroid or glucocortoid* or glycocorticoid or glycocorticosteroid).mp.

4 exp dexamethasone/

5 (Dexamethasone* or fluoroprednisolone or corticosterone or adrecort or adrenocot or aeroseb dex or aflucoson* or alfalyl or anaflogistico or arcodexan* or artrosone or azium or bidexol).mp.

6 exp methylprednisolone/

(methylprednisolone or 6 methyl delta 1 hydrocortisone or 6 methyl prednisolone or 6 methylprednisolone or 6alpha methyl deltal hydrocortisone or adlone-40 or adlone 80 or adlone- 80 or adlone 40 or depmedalone or dep medalone or depoject-80 or depoject 80 or depopred

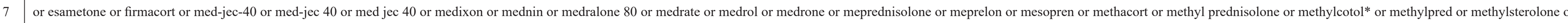
metidrol or metrisone or metycortin or metypred or metypresol or neomedrone or nsc 19987 or nsc 19987 or prednol or solomet or solu decortin or urbason).mp.

(Dexamethasone* or adrecort or adrenocot or aeroseb dex or aflucoson* or alfalyl or anaflogistico or arcodexan* or artrosone or azium or bidexol or calonat or cebedex or cetadexon or colofoam or corsona* or cortastat or cortidex* or cortisumman or cortidron* or dacortina fuerte or dacortine fuerte or dalalone or danasone or de-sone la or decacortin or decadeltoson* or decaderm or decadion or decadran or decadron* decaesadril or decaject or decameth* or decasone or decaspray or decasterolone or decdan or decilone or decofluor* or dectancyl or dekacor or delladec or deltafluoren* or dergramin or deronil or desacort or desacortone or desalark or desameton* or desigdron or dexa cortisyl or dexa dabrosan or dexa korti or dexa scherosan or dexa scherozon or dexa-pdexa-p or dexacort* or dexacortin or dexacortin or dexadabroson

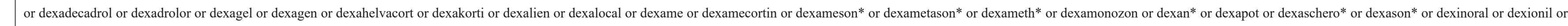
dexmethsone or dexon* or dexpak or dextelan or dextrasone or dezone or dibasona or doxamethasone or esacortene or exadion* or firmalone or fluormethyl prednisolon* or fluormethylprednisolon or fluormone or fluorocort or fluorodelta or fluoromethylprednisolone or fortecortin or gammacorten* or grosodexon* or hexadecadiol or hexadecadrol or hexadiol or hexadrol or isnacort or isopto dex or isopto maxidex or isoptodex or isoptomaxidex or lokalison for loverine or luxazone or marvidione or maxidex or mediamethasone or megacortin or mephameson* or metasolon* or methazon* ion or methazonion* or metisone lafi or mexasone or millicorten* or mk 125 or mymethasone or neoforde* or nisomethasona or novocort or nsc 34521 or nsc 34521 or oftan-dexa or opticort* or oradex* or orgadrone or ozurdex or pidexon or policort or posurdex or predni for prednisolone $\mathrm{f}$ or prodexona or prodexone or sanamethasone or santenson or santeson or sawasone or solurex or spoloven or sterasone or thilodexine or triamcimetil or vexamet or visumetazone or visumethazone).mp.

9 exp prednisolone/

(prednisolone or pregnadien* or adelcort or antisolon or antisolone or aprednislon or aprednislone or benisolon or benisolone or berisolon or berisolone or caberdelta or capsoid or co-hydeltra or co hydeltra or codelcortone or compresolon or cortadeltona or cortadeltone or cortalone or cortelinter or cortisolone or cotolone or dacortin or dacrotin or decaprednil or decorti* or dehydro cortex or dehydro hydrocortison* or dehydrocortex or dehydrocortisol or dehydrocortisole or dehydrohydrocortison or dehydrohydrocortisone or delcortol or hydroxycorticosterone or hydrocortisone or delta cortef or delta cortril or delta ef cortelan or delta hycortol or delta hydrocortison* or delta ophticor or delta stab or deltal dehydrocortisol* or deltal hydrocortisone or deltacortef or deltacortenolo or deltacortil or deltacortoil or deltacortril or deltaderm or deltaglycortril or deltahycortol or deltahydrocortison* or deltaophticor or deltasolone or deltastab or deltidrosol or deltisilone or deltisolon* or deltolasson* or deltosona or deltosone or depo-predate or depo predate or dermosolon* or di adreson for diadreson for di adresone f or

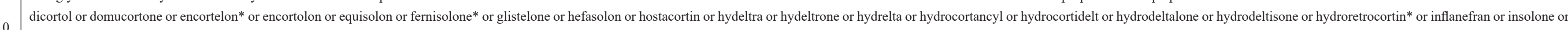

keteocort or key-pred or lenisolone or leocortol or liquipred or lygal kopftinktur or mediasolone or meprisolon* or metacortalon* or metacortandralon or metacortandralone or metacortelone or meti derm or meticortelone or metiderm or morlone or mydrapred or neo delta or nisolon or nisolone or nsc 9120 or nsc 9120 or opredsone or panafcortelone or panafcortolone or panafort or paracortol or phlogex or pre cortisyl or preconin or precortalon or precortancyl or precortisyl or pred-ject-50 or pred ject 50 or predacort or predaject or predalone or predartrina or predartrine or predate or predeltilone or predisole or predisyr or predne dome or prednecort or prednedome or prednelan or predni coelin or predni h tablinen or predni-helvacort or predni helvacort or prednicoelin or prednicort* or prednifor or predniment or predniretard or prednis or prednivet or prednorsolon* or predonine or predorgasolon* or prelon or prelone or prenilone or prenin or prenolone or preventan or prezolon or rubycort or scherisolon or scherisolona or serilone or solondo or solone or solupren or soluprene or spiricort or spolotane or sterane or sterolone or supercortisol or supercortizol or taracortelone or walesolone or wysolone).mp.

11 exp betamethasone/

(16beta methyl 9alpha fluoro delta 1 hydrocortisone or 16beta methyl 9alpha fluoroprednisolone or 9alpha fluoro 11 beta or 9alpha fluoro 16beta methyl* or 9alpha fluoro 16beta methylprednisolone or adbeon or becasone or benoson or beprogel or beta methason or beta methasone

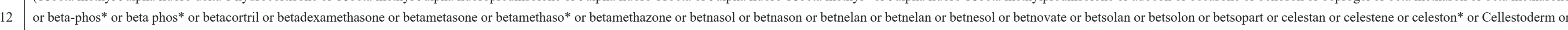
cidoten or dermobet or diprolen or flubenisolone or methasone or nsc 39470 or nsc 39470 or prednisolone or pregna $1^{*}$ or $\mathrm{rg} 833$ or rg8 833 or rinderon or sch 4831 or sch 4831 or walacort).mp.

13 exp molar tooth

14 (third Molar* or Wisdom Tooth or Wisdom Teeth).mp.

\begin{tabular}{l|l|l}
15 & 13 or 14
\end{tabular}

\begin{tabular}{l|l}
\hline 16 & or $/ 1-12$ \\
\hline 17 & 15
\end{tabular}

\begin{tabular}{l|l}
17 & 15 and 16
\end{tabular}

18 remove duplicates from 17 
Appendix 3. Cochrane Library search until the $1^{\text {st }}$ of December 2017

\begin{tabular}{|c|c|c|}
\hline ID & Search terms & $\begin{array}{c}\text { Number of } \\
\text { hits }\end{array}$ \\
\hline 1 & MeSH descriptor: [Adrenal Cortex Hormones] explode all trees & 13030 \\
\hline 2 & MeSH descriptor: [Dexamethasone] explode all trees & 2603 \\
\hline 3 & MeSH descriptor: [Methylprednisolone] explode all trees & 1698 \\
\hline 4 & MeSH descriptor: [Prednisolone] explode all trees & 3591 \\
\hline 5 & MeSH descriptor: [Betamethasone] explode all trees & 1093 \\
\hline 7 & Dexamethasone* or fluoroprednisolone or corticosterone or adrecort or adrenocot or aeroseb dex or aflucoson* or alfalyl or anaflogistico or arcodexan* or artrosone or azium or bidexol & 7648 \\
\hline 8 & $\begin{array}{l}\text { methylprednisolone or } 6 \text { methyl delta } 1 \text { hydrocortisone or } 6 \text { methyl prednisolone or } 6 \text { methylprednisolone or 6alpha methyl deltal hydrocortisone or adlone- } 40 \text { or adlone } 80 \text { or adlone- } 80 \text { or adlone } 40 \text { or depmedalone or dep medalone or depoject- } 80 \text { or depoject } 80 \text { or depopred or } \\
\text { esametone or firmacort or med-jec- } 40 \text { or med-jec } 40 \text { or med jec } 40 \text { or medixon or mednin or medralone } 80 \text { or medrate or medrol or medrone or meprednisolone or meprelon or mesopren or methacort or methyl prednisolone or methylcotol* or methylpred or methylsterolone or } \\
\text { metidrol or metrisone or metycortin or metypred or metypresol or neomedrone or nsc } 19987 \text { or nsc } 19987 \text { or prednol or solomet or solu decortin or urbason }\end{array}$ & 4282 \\
\hline 9 & $\begin{array}{l}\text { Dexamethasone* or adrecort or adrenocot or aeroseb dex or aflucoson* or alfalyl or anaflogistico or arcodexan* or artrosone or azium or bidexol or calonat or cebedex or cetadexon or colofoam or corsona* or cortastat or cortidex* or cortisumman or cortidron* or dacortina fuerte } \\
\text { or dacortine fuerte or dalalone or danasone or de-sone la or decacortin or decadeltoson* or decaderm or decadion or decadran or decadron* decaesadril or decaject or decameth* or decasone or decaspray or decasterolone or decdan or decilone or decoffluor* or dectancyl or dekacort } \\
\text { or delladec or deltafluoren* or dergramin or deronil or desacort or desacortone or desalark or desameton* or desigdron or dexa cortisyl or dexa dabrosan or dexa korti or dexa scherosan or dexa scherozon or dexa-pdexa-p or dexacort* or dexacortin or dexacortin or dexadabroson } \\
\text { or dexadecadrol or dexadrolor or dexagel or dexagen or dexahelvacort or dexakorti or dexalien or dexalocal or dexame or dexamecortin or dexameson* or dexametason* or dexameth* or dexamonozon or dexan* or dexapot or dexaschero* or dexason* or dexinoral or dexionil or } \\
\text { dexmethsone or dexon* or dexpak or dextelan or dextrasone or dezone or dibasona or doxamethasone or esacortene or exadion* or firmalone or fluormethyl prednisolon* or fluormethylprednisolon or fluormone or fluorocort or fluorodelta or fluoromethylprednisolone or fortecortin } \\
\text { or gammacorten* or grosodexon* or hexadecadiol or hexadecadrol or hexadiol or hexadrol or isnacort or isopto dex or isopto maxidex or isoptodex or isoptomaxidex or lokalison for loverine or luxazone or marvidione or maxidex or mediamethasone or megacortin or mephameson* } \\
\text { or metasolon* or methazon* ion or methazonion* or metisone lafi or mexasone or millicorten* or mk } 125 \text { or mymethasone or neoforde* or nisomethasona or novocort or nsc } 34521 \text { or nsc } 34521 \text { or oftan-dexa or opticort* or oradex* or orgadrone or ozurdex or pidexon or policort or } \\
\text { posurdex or predni for prednisolone for prodexona or prodexone or sanamethasone or santenson or santeson or sawasone or solurex or spoloven or sterasone or thilodexine or triamcimetil or vexamet or visumetazone or visumethazone }\end{array}$ & 8663 \\
\hline 10 & 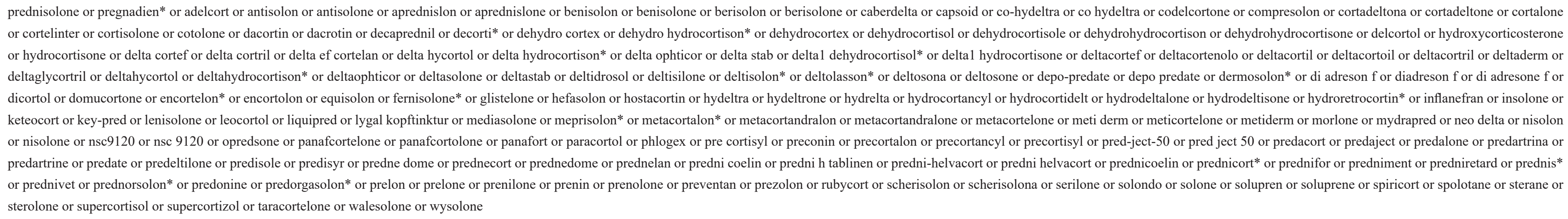 & 20987 \\
\hline 11 & $\begin{array}{l}\text { 16beta methyl 9alpha fluoro delta } 1 \text { hydrocortisone or } 16 \text { beta methyl 9alpha fluoroprednisolone or 9alpha fluoro } 11 \text { beta or } 9 \text { alpha fluoro } 16 \text { beta methyl* or } 9 \text { alpha fluoro } 16 \text { beta methylprednisolone or adbeon or becasone or benoson or beprogel or beta methason or beta methasone } \\
\text { or beta-phos* or beta phos* or betacortril or betadexamethasone or betametasone or betamethaso* or betamethazone or betnasol or betnason or betnelan or betnelan or betnesol or betnovate or betsolan or betsolon or betsopart or celestan or celestene or celeston* or Cellestoderm or } \\
\text { cidoten or dermobet or diprolen or flubenisolone or methasone or nsc } 39470 \text { or nsc } 39470 \text { or prednisolone or pregna } 1 * \text { or rg } 833 \text { or rg } 833 \text { or rinderon or sch } 4831 \text { or sch } 4831 \text { or walacort }\end{array}$ & 9018 \\
\hline 12 & $\# 1$ or $\# 2$ or $\# 3$ or $\# 4$ or $\# 5$ or $\# 6$ or $\# 7$ or $\# 8$ or $\# 9$ or $\# 10$ or $\# 11$ & 48121 \\
\hline 13 & MeSH descriptor: [Molar, Third] explode all trees & 881 \\
\hline 16 & $\# 12$ and \#15 & 183 \\
\hline
\end{tabular}

